\title{
Specific Early and Late Oddball-Evoked Responses in Excitatory and Inhibitory Neurons of Mouse Auditory Cortex
}

\author{
I-Wen Chen, ${ }^{1,2}$ Fritjof Helmchen, ${ }^{1,2}$ and Henry Lütcke ${ }^{1,3}$ \\ ${ }^{1}$ Laboratory of Neural Circuit Dynamics, Brain Research Institute, University of Zurich, CH-8057, Zurich, Switzerland, ${ }^{2}$ Neuroscience Center Zurich, \\ University of Zurich and ETH Zurich, CH-8057, Zurich, Switzerland, and ${ }^{3}$ Scientific IT Services, ETH Zurich, CH-8092, Zurich, Switzerland
}

\begin{abstract}
A major challenge for sensory processing in the brain is considering stimulus context, such as stimulus probability, which may be relevant for survival. Excitatory neurons in auditory cortex, for example, adapt to repetitive tones in a stimulus-specific manner without fully generalizing to a low-probability deviant tone ("oddball") that breaks the preceding regularity. Whether such stimulus-specific adaptation (SSA) also prevails in inhibitory neurons and how it might relate to deviance detection remains elusive. We obtained whole-cell recordings from excitatory neurons and somatostatin- and parvalbumin-positive GABAergic interneurons in layer 2/3 of mouse auditory cortex and measured tone-evoked membrane potential responses. All cell types displayed SSA of fast ("early") subthreshold and suprathreshold responses with oddball tones of a deviant frequency eliciting enlarged responses compared with adapted standards. SSA was especially strong when oddball frequency matched neuronal preference. In addition, we identified a slower "late" response component (200 - $400 \mathrm{~ms}$ after tone onset), most clearly in excitatory and parvalbumin-positive neurons, which also displayed SSA. For excitatory neurons, this late component reflected genuine deviance detection. Moreover, intracellular blockade of NMDA receptors reduced early and late responses in excitatory but not parvalbumin-positive neurons. The late component in excitatory neurons thus shares time course, deviance detection, and pharmacological features with the deviant-evoked event-related potential known as mismatch negativity (MMN) and provides a potential link between neuronal SSA and MMN. In summary, our results suggest a two-phase cortical activation upon oddball stimulation, with oddball tones first reactivating the adapted auditory cortex circuitry and subsequently triggering delayed reverberating network activity.
\end{abstract}

Key words: auditory cortex; interneurons; mismatch negativity; mouse; stimulus-specific adaptation

\section{Significance Statement}

Understanding how the brain encodes sensory context in addition to stimulus feature has been a main focus in neuroscience. Using in vivo targeted whole-cell recordings from excitatory and inhibitory neurons of mouse primary auditory cortex, we report two temporally distinct components of membrane potential responses encoding oddball tones that break stimulus regularity. Both components display stimulus-specific adaptation upon oddball paradigm stimulation in the three recorded cell types. The late response component, in particular, carries signatures of genuine deviance detection. In excitatory but not parvalbuminpositive inhibitory neurons, both early and late components depend on NMDA receptor-signaling. Our work proposes a potential neuronal substrate of a known deviant-evoked event-related potential, which is of fundamental significance in basic and clinical neuroscience.

\section{Introduction}

Information processing in the mammalian auditory system is hierarchically organized, with physical sound features extracted near the periphery and contextual features such as stimulus probability being increasingly integrated along the ascending auditory pathway. For example, in primary auditory cortex (A1), stimulus-specific adapta-
Received June 10, 2015; revised July 30, 2015; accepted Aug. 4, 2015.

Author contributions: I.-W.C., F.H., and H.L. designed research; I.-W.C. performed research; H.L. contributed unpublished reagents/analytic tools; I.-W.C., F.H., and H.L. analyzed data; I.-W.C., F.H., and H.L. wrote the paper.

This work was supported by the Forschungskredit of the University of Zurich (H.L.), the Hartmann-Müller Stiftung (H.L.), a grant from the Novartis Foundation for Medical Biological Research (H.L., F.H.), the National Centre of Competence in Research "Neural Plasticity and Repair" of the Swiss National Science Foundation (F.H.), the Swiss SystemsX.ch initiative (F.H.), and by a Roche Postdoctoral Fellowship awarded to H.L. We thank H. Kasper, R.
Krüppel, M. van't Hoff, and F. Voigt for technical assistance, and U. Gerber for helpful discussion and providing MK-801.

The authors declare no competing financial interests.

Correspondence should be addressed to either of the following: Dr. Henry Lütcke, ETH Zurich, Weinbergstr 11, CH-8092, Zurich, Switzerland, E-mail: hluetcke@ethz.ch; or Prof. Fritjof Helmchen, Brain Research Institute, Univer sity of Zurich, CH-8057, Zurich, Switzerland, E-mail: helmchen@hifo.uzh.ch.

DOI:10.1523/JNEUROSCI.2240-15.2015

Copyright $\odot 2015$ the authors $\quad 0270-6474 / 15 / 3512560-14 \$ 15.00 / 0$ 
tion (SSA) has been reported as the decrease in neuronal response to repeating "standard" tones, which does however not fully generalize to a rare and irregular "oddball” tone (Nelken, 2014; Pérez-González and Malmierca, 2014). In extracellular recording experiments, SSA occurring tens of milliseconds after tone onset has been identified in A1 of various mammalian species (Ulanovsky et al., 2003; von der Behrens et al., 2009; Taaseh et al., 2011; Fishman and Steinschneider, 2012), as well as subcortically in inferior colliculus (Malmierca et al., 2009; Duque et al., 2012) and auditory thalamus (Anderson et al., 2009). Similarly, a prominent electroencephalographic (EEG) signal known as "mismatch negativity" (MMN), typically peaking $~ 100-$ $250 \mathrm{~ms}$ after stimulus onset, is evoked by deviant tones in the human and animal brain. Functionally, MMN reflects a break in a preceding regularity, i.e., a change in a repetitive stimulus sequence, and thus represents genuine deviance detection (Näätänen et al., 2007; Grimm et al., 2011; Fishman and Steinschneider, 2012). Although SSA has been speculated to be a neuronal substrate of MMN (Ulanovsky et al., 2003; von der Behrens, 2009), their precise relationship remains elusive (Garrido et al., 2009; May and Tiitinen, 2010), largely because the cortical circuit mechanisms underlying SSA and MMN are incompletely understood and their different time courses have not yet been reconciled. Understanding neuronal circuit dynamics underlying brain responses to specific stimulus contexts, such as a rare, regularity-breaking deviant stimulus, is of great importance, because macroscopic signals, such as MMN, are altered in a number of neuropsychiatric diseases, for example schizophrenia (Shelley et al., 1991; Todd et al., 2012).

To better understand circuit mechanisms underlying SSA and MMN, intracellular recordings of membrane potential dynamics from identified neuronal subtypes are desirable. Previous wholecell recordings from rat A1 excitatory neurons revealed tuning properties of excitatory and inhibitory synaptic conductances and their temporal sequence following auditory stimulation (Wehr and Zador, 2003; Zhang et al., 2003; Tan and Wehr, 2009). Only recently intracellular sharp recordings confirmed SSA at subthreshold level using a frequency-oddball paradigm (Hershenhoren et al., 2014). Critically, auditory responsiveness and adaptation properties of diverse classes of inhibitory interneurons in A1 neuronal circuitry have not been determined. Because not all synapses in A1 are depressing but some GABAergic interneurons even receive facilitating inputs (Levy and Reyes, 2012), neuronal inhibition may variably contribute to cortical SSA. Two major subtypes of genetically defined GABAergic cells, the somatostatin (SST)-expressing and parvalbumin (PV)-expressing interneurons, could be differentially involved in SSA as they inhibit distal dendrites and perisomatic regions, respectively (Adesnik et al., 2012; Wilson et al., 2012). Other A1 interneurons may enhance excitation during SSA by disinhibiting other interneurons (Letzkus et al., 2011; Pi et al., 2013). Moreover, GABAerigc interneurons along the auditory pathway may provide gain control to modulate SSA magnitude (Pérez-González et al., 2012; Duque et al., 2014). Although a recent study applied intracellular recordings from SST and PV interneurons to compare tonal receptive fields (Li et al., 2014), oddball responses and SSA in the diverse interneuron classes so far have remained unexplored.

Here we used two-photon-guided whole-cell recordings (Margrie et al., 2003; Kitamura et al., 2008) in layer 2/3 (L2/3) of mouse A1 to characterize membrane potential dynamics upon oddball paradigm stimulation in excitatory pyramidal neurons as well as GABAergic SST and PV interneurons. Our data show that SSA is present in the early responses of all three cell types. Further, we discovered a secondary late response component, especially in pyramidal neurons and PV interneurons, which is triggered by deviant tones and shares temporal and pharmacological characteristics with MMN. Our results offer a refined view of contextdependent stimulus processing in the heterogeneous cortical microcircuit, indicating two temporally distinct phases of oddball processing: an initial early phase of reactivation of cortical circuit elements, including inhibitory interneurons, presumably through recruitment of nonadapted pathways; and a subsequent secondary, longer-lasting phase, likely reflecting broader reverberating network activity or corticocortical feedback.

\section{Materials and Methods}

Animals and surgical preparation. Experimental procedures conformed to the guidelines of the Swiss Federal Veterinary Office and were approved by the Cantonal Veterinary Office in Zurich. We used different transgenic mouse lines to identify specific neuronal cell types, especially GABAergic interneurons expressing SST and PV, respectively, which form largely nonoverlapping populations and together comprise $\sim 66 \%$ of cortical interneurons (Rudy et al., 2011). SST-IRES-Cre mice (Jackson Laboratories, no. 013044); Hippenmeyer et al., 2005) or PV-IRES-Cre mice (Jackson Laboratories, no. 008069; Taniguchi et al., 2011) were crossed with a tdTomato reporter line (Jackson Laboratories, no. 007914; Madisen et al., 2010), resulting in offspring mice expressing red fluorescent protein tdTomato in SST and PV neurons, respectively. A subset of recordings from pyramidal neurons was obtained from wild-type (WT) mice or another transgenic mouse line with GFP-expressing GABAergic neurons (GAD67; Tamamaki et al., 2003). In total, 44 mice were used (6 GAD67, 1 WT, 22 SST $\times$ tdTomato and $15 \mathrm{PV} \times$ tdTomato mice), giving rise to 27 measurements for pyramidal neurons ( 9 cells from GAD67, 2 from WT, 9 from SST lines, and 7 from PV lines), 27 for SST interneurons, and 15 for PV interneurons for tuning experiments. Because the recording quality varied over time, only a subset of the recordings was chosen for different analyses $(n=21,20$, and 11 for Exc, SST, and PV neurons for analyzing membrane potential dynamics; $n=20,20$, and 12 for Exc, SST, and PV cells for SSA analysis). For MK-801 experiments, an additional dataset of 11 pyramidal neurons and 9 PV interneurons was collected from $14 \mathrm{PV} \times$ tdTomato mice.

Young adult male or female mice (age 5-10 weeks) were anesthetized with $1.5 \%$ isoflurane during surgery ( $4 \%$ during induction). Left primary Al was identified by stereotactic coordinates $(2.5 \mathrm{~mm}$ posterior of bregma, $4.5 \mathrm{~mm}$ lateral of midline), as well as intrinsic optical imaging through the thinned skull. We illuminated the cortical surface with 630 $\mathrm{nm}$ LED light and collected the tissue reflectance signal with a CCD camera (Toshiba TELI-CS3960DCL) through a $4 \times$ objective (Olympus). A1 was localized by presenting pure tones $(8,10$, or $12 \mathrm{kHz})$ at $60-80 \mathrm{~dB}$ sound pressure level (SPL) and locating the area of largest reflectance decrease. A small craniotomy $(\sim 1 \times 1 \mathrm{~mm})$ was performed above the identified Al and the dura mater removed. Agarose $(<2 \%$ in Ringer solution) and a cover glass were applied on top of the craniotomy to dampen tissue movement. Animals were kept under light isofluraneanesthesia $(0.5-1 \%)$ during the experiment and breathing rate was frequently monitored ( $\geq 1$ breaths/s).

Two-photon guided in vivo whole-cell recordings. Neurons in supragranular cortical layers $(<300 \mu \mathrm{m}$, layer 1 and layer $2 / 3)$ were targeted with patch pipettes under a custom-built two-photon microscope system installed in a sound-proofed compartment, equipped with a Ti:sapphire laser (Mai Tai DeepSee or Tsunami; Spectra-Physics), a Pockels cell (Conoptics), galvanometric scan mirrors (Cambridge Technology), and a $16 \times$ water-immersion objective (NA 0.8; Nikon). Cells were visualized using $930 \mathrm{~nm}$ excitation and by collecting fluorescence through red $(610 / 75 \mathrm{~nm})$ and green $(535 / 50 \mathrm{~nm})$ emission filters (AHF Analysentechnik). Image acquisition was controlled with HelioScan, a LabVIEW-based custom microscope software framework (Langer et al., 2013).

Electrophysiological recordings were obtained with glass pipettes (4-7 $\mathrm{M} \Omega$ resistance) filled with control internal solution (without MK-801) containing the following (in mM): 135 potassium gluconate, 10 HEPES, 10 sodium phosphocreatine, $4 \mathrm{KCl}, 4 \mathrm{Mg}$-ATP, $0.3 \mathrm{Na}_{3} \mathrm{GTP}$, and 20 AlexaFluor 488 (Invitrogen) for pipette visualization. Extracellular solution contained the following (in mM): $145 \mathrm{NaCl}, 5.4 \mathrm{KCl}, 10$ HEPES, 1 
Table 1. Electrophysiological properties of pyramidal neurons, and SST and PV interneurons in L2/3 of mouse auditory cortex

\begin{tabular}{lcrr}
\hline Parameter & Pyramidal neurons & SST interneurons & PV interneurons \\
\hline Average membrane potential $(\mathrm{mV})$ & $-74.1 \pm 0.9(n=21)$ & $-63.3 \pm 1.6(n=20)$ & $-66.3 \pm 1.8(n=11)$ \\
Resting membrane potential $(\mathrm{mV})$ & $-78.0 \pm 0.7(n=21)$ & $-65.7 \pm 1.7(n=20)$ & $-72.2 \pm 1.5(n=11)$ \\
Input resistance $(\mathrm{M} \Omega)$ & $51.1 \pm 2.9(n=21)$ & $97.9 \pm 6.2(n=20)$ & $43.9 \pm 7.8(n=11)$ \\
AP half-width $(\mathrm{ms})$ & $1.65 \pm 0.07(n=20)$ & $1.02 \pm 0.06(n=20)$ & $0.56 \pm 0.04(n=11)$ \\
AP threshold $(\mathrm{mV})$ & $-40.9 \pm 1.3(n=20)$ & $-41.4 \pm 1.0(n=20)$ & $-46.4 \pm 0.9(n=11)$ \\
Spontaneous spiking rate $(\mathrm{Hz})$ & $0.03 \pm 0.01(n=19)$ & $1.3 \pm 0.3(n=14)$ & $9.3 \pm 3.1(n=11)$ \\
Maximum spiking rate* $(\mathrm{Hz})$ & $45.5 \pm 5.2(n=18)$ & $75.7 \pm 9.0(n=19)$ & $163.3 \pm 20.0(n=11)$ \\
\hline
\end{tabular}

Data are given as mean \pm SEM.

The dataset for analyzing electrophysiological properties is 21 Exc neurons, 20 SST neurons, and 11 PV neurons. The smaller sample size of some parameters for pyramidal neurons and SST interneurons is due to the lack of APs in few recordings.

*Maximum spiking rates are underestimates of the true maximum rates.

$\mathrm{MgCl}_{2}$, and $1.8 \mathrm{CaCl}_{2}$. Membrane potential recordings were corrected for liquid junction potential $(-10.3 \pm 0.6 \mathrm{mV}, n=13$ measurements). Voltage recordings were performed with an Axoclamp 2B amplifier (Molecular Devices), preamplified and digitized at $20 \mathrm{kHz}$ with an ITC-18 board (InstruTECH) controlled by custom-written IGOR Pro software (WaveMetrics). Small positive pressure (20-30 mbar) was applied while navigating the pipette in the tissue with a micromanipulator (Luigs and Neumann). Two-photon-guided whole-cell recordings from fluorescent SST or PV neurons and from putative pyramidal neurons, identified as unlabeled "shadow" cells, were obtained as described previously (Margrie et al., 2003; Kitamura et al., 2008). After establishing whole-cell configuration, current pulses of 300-400 ms were injected to measure basic electrophysiological parameters (Table 1). No holding current was applied in current-clamp mode. Access resistance was estimated by applying brief negative current test pulses ( $<1 \mathrm{nA}, 20 \mathrm{~ms}$ pulse-width) and compensated on-line. Cells were discarded if initial access resistance was $>70 \mathrm{M} \Omega$. For measuring tuning receptive fields and performing oddball experiments (see below), total recording durations of $1-1.5 \mathrm{~h}$ were required, during which neurons were held in whole-cell configuration and recording quality was constantly monitored. To confirm cell identity and cell morphology, fluorescence image stacks were acquired at the end of the experiment.

For MK-801 experiments, we added $267 \mu \mathrm{M}$ MK-801 (Tocris Bioscience) to the control internal solution. To minimize MK-801 contamination during pipette navigation, the pipette was back-filled with $2 \mu \mathrm{l}$ control internal solution, and then with $7 \mu \mathrm{l}$ solution containing MK801 . The estimated final pipette concentration of MK-801 was $207 \mu \mathrm{M}$. MK-801 is an irreversible, use-dependent NMDA-receptor antagonist. To ensure sufficient blockage of NMDA receptors, oddball responses were measured at least 15 min after pipette break-in.

Auditory stimulation. Auditory stimuli (pure tones with $5 \mathrm{~ms}$ rise and fall time) were generated with a Tucker-Davis System 3 processor (RZ6) and presented in free-field configuration with an electrostatic loudspeaker (ES1, Tucker-Davis). A grounded small faraday cage built around the loudspeaker prevented electromagnetic interference with electrophysiological recordings. The loudspeaker was placed $\sim 5 \mathrm{~cm}$ from the contralateral (right) ear of the animal. To reduce ambient acoustic noise, the recording chamber and the laser system were shielded with sound-proofing foam. The transfer function of the sound system was measured with a condenser microphone (PCB Piezotronics) and calibrated using SigCalRP (Tucker-Davis). The sound system was calibrated for frequency ranges of 4-50 kHz. After calibration, there was an intensity deviation of $\pm 11 \mathrm{~dB}$ across the frequency range for a desired sound pressure level. At zero attenuation level, the sound intensity was 90 dB SPL. Intensities of 70-90 dB were used for tuning curve measurements. Sound intensity was $80 \mathrm{~dB}$ during the oddball paradigm. The ambient noise of the experimental setup was $\sim 60 \mathrm{~dB}$ (mainly caused by the laser cooling system) predominated by low frequencies $(<5 \mathrm{kHz})$, for which mice have high hearing thresholds.

Oddball experiment design. Determining frequency tuning is a prerequisite for selecting two appropriate frequencies in the oddball paradigm. For each recorded neuron, frequency selectivity was determined by measuring neuronal responses to pseudorandom blocks of pure tones ranging from 4.00 to $45.26 \mathrm{kHz}$ [0.25 octave apart, 15 frequencies, $100 \mathrm{~ms}$ duration, $800 \mathrm{~ms}$ interstimulus interval (ISI) onset-to-onset], alternately presented at sound intensities of 0,10 , and $20 \mathrm{~dB}$ attenuation levels (corresponding to 90,80 , and $70 \mathrm{~dB}$ ). Each block contained 60 tones (4 repetitions per frequency). For each sound intensity, two to four blocks of pure tones were presented (8-16 repetitions per frequency). The best frequency $(\mathrm{BF})$ of the recorded neurons was determined as the frequency that evoked the largest response. Due to recording time constraints we determined a coarse tuning curve for frequency-selection for the oddball paradigm in the subsequent experiment, with only a limited set of tone intensities (3) and tone frequencies (15) presented. We therefore do not report detailed tuning receptive fields in the three A1 cell types here. We note that the pseudorandom sequence of pure tones at $80 \mathrm{~dB}$ was also used as the "many-standards" paradigm to test the presence of deviance detection.

After determining the neuron's BF, the frequency-oddball experiment was designed by selecting two frequencies $\left(f_{1}\right.$ and $\left.f_{2}\right)$ within the TRF and separated by $\Delta \mathrm{f}=0.5$ octaves (Fig. $1 A$ ). Both $f_{1}$ and $f_{2}$ were pseudorandomly assigned as either oddball or standard tone in alternate blocks. For the main oddball experiment, the probability of the oddball tone $\left(P_{\text {Odd }}\right)$ was 0.1 (100 oddball trials and 900 standard trials in 10 stimulation blocks), with additional constraint that at least six standard tones occurred between oddballs. As control conditions, we further included blocks with $P_{\text {Odd }}=0.3$ (120 oddball trials and 240 standard trials in 4 stimulation blocks) and $P_{\text {Odd }}=0.5$ (100 oddball trials and 100 standard trials in 2 stimulation blocks). All tones were presented with $100 \mathrm{~ms}$ duration and $500 \mathrm{~ms}$ ISI.

Data analysis. All data analysis was performed with MATLAB (MathWorks). The average membrane potential of each neuron was estimated as the mean membrane potential during the first $100 \mathrm{~ms}$ of currentinjection protocol (before injection of a $300-400 \mathrm{~ms}$ step-current pulse). The resting membrane potential was measured by manually selecting traces at DOWN-states without action potentials (APs) during the same time period. AP threshold was inferred as the voltage at the time corresponding to local maximum of the third derivative from the membrane potential (down-sampled to $10 \mathrm{kHz}$; Gentet et al., 2010). AP amplitude was measured from threshold-to-peak and AP half-width was estimated as the full width at half-maximal amplitude. The $I-V$ curve was fitted with a quadratic function and input resistance was calculated as the slope at zero current. Baseline firing rate (FR) was estimated during the initial frequency-tuning experiment within the periods before and after sound stimulation (no baseline firing assumed for cells exhibiting spiking rates $<0.1 \mathrm{~Hz}$ ). Subthreshold membrane potential $\left(V_{\mathrm{m}}\right)$ changes were estimated by removing APs from the original voltage recordings using median filtering (Hershenhoren et al., 2014; Li et al., 2014). $V_{\mathrm{m}}$ response amplitude was calculated as the peak amplitude relative to a $10 \mathrm{~ms}$ baseline period before tone onset for the early time window $(0-100 \mathrm{~ms}$ after tone onset) and as mean amplitude relative to baseline for the late time window (200-400 ms after tone onset). Because SST cells, in particular, display tone-evoked early hyperpolarization (Fig. 1), the peak response amplitude provides a better estimate of the immediate excitatory drive. FR changes were calculated in $20 \mathrm{~ms}$ bins. Tone-evoked onset latency was estimated as the earliest time point when the average response reached mean +1 SD prestimulus baseline 10 ms before tone onset ( $\mathrm{Li}$ et al., 2014). 

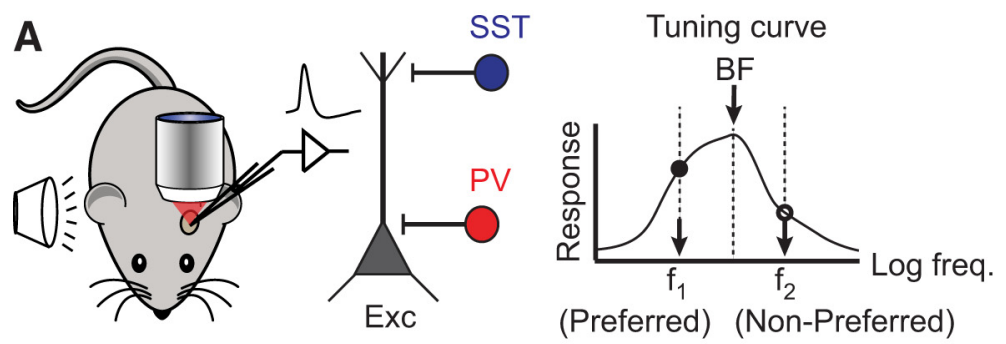

\section{Oddball paradigm}

B

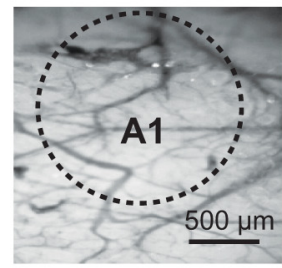

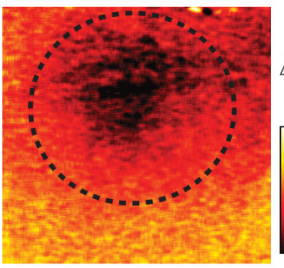

C

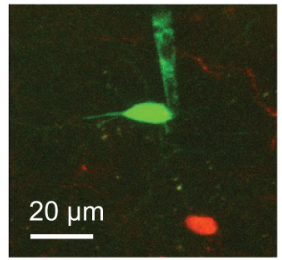

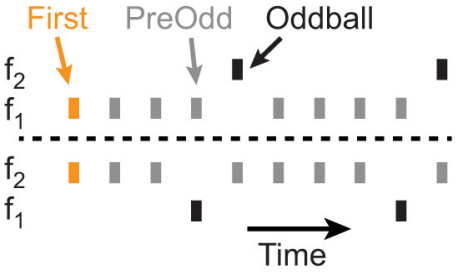

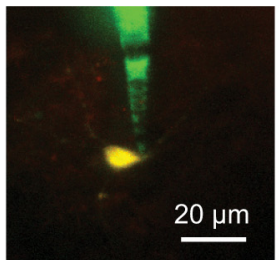

SST

PV
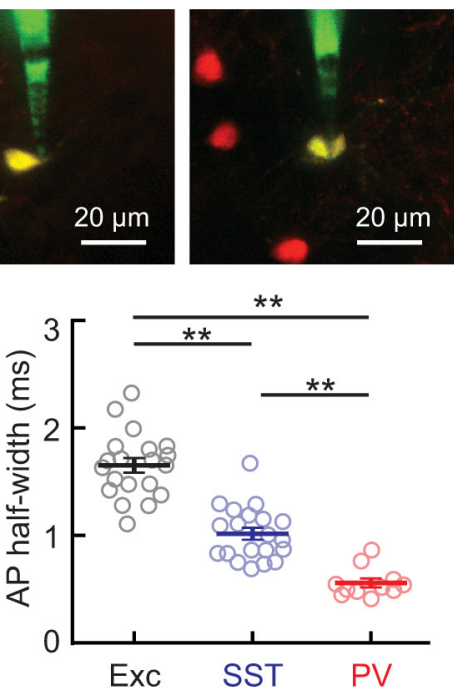

D

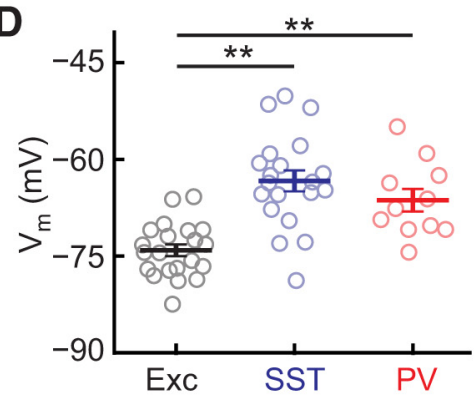

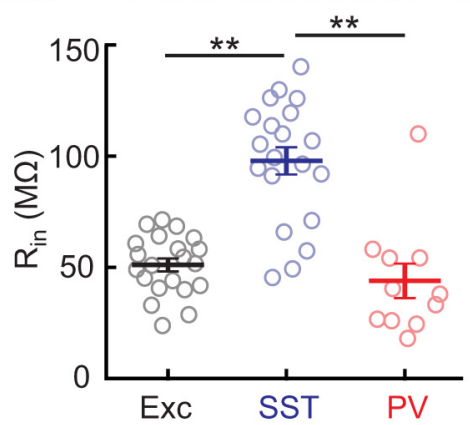

E

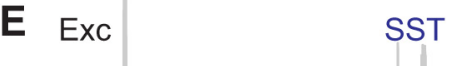

$V_{m}$

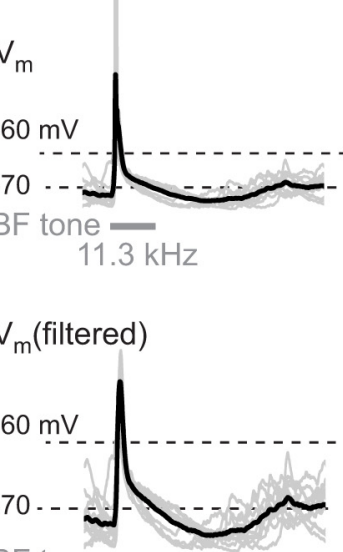

BF tone -

Firing rate (FR)

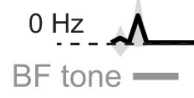

PV

$$
\frac{20 \mathrm{mV}}{0.2 \mathrm{~s}}
$$

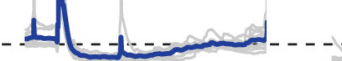

$26.9 \mathrm{kHz}$
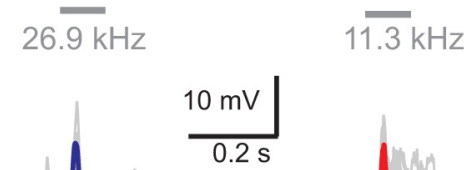

$11.3 \mathrm{kHz}$
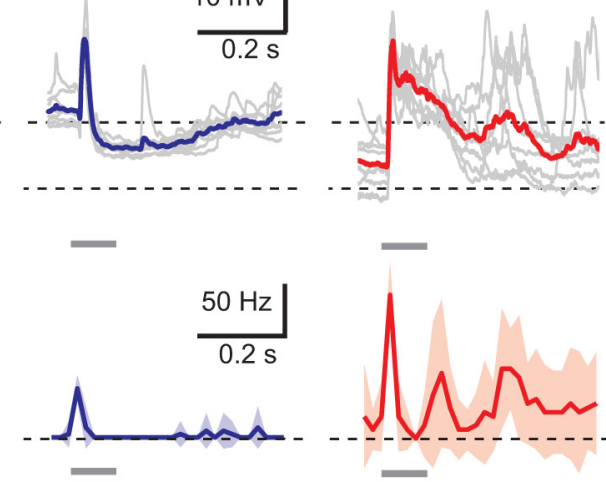

F
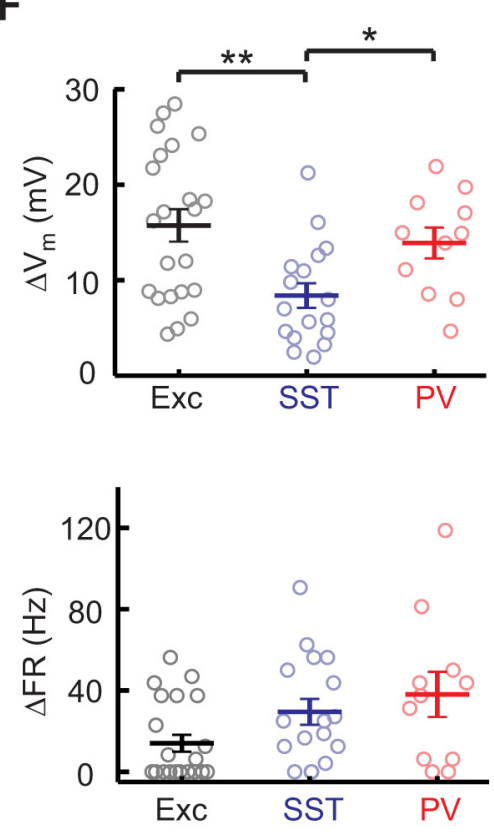

Figure 1. Tone-evoked membrane potential responses of neurons in mouse auditory cortex. A, Schematic of experimental design. Left, Whole-cell recordings were obtained from Exc neurons (black), SST (blue) and PV (red) interneurons in L2/3 of A1. Middle, Two sound frequencies $f 1$ and $f 2$, distributed around the BF, were chosen from the tuning curve. Due to asymmetry of the tuning curve, $f 1$ and $f 2$ typically differed in their evoked response amplitudes, referred to here as preferred and nonpreferred frequencies. Right, In an oddball paradigm repeated standard tones of one frequency ( $f 1$ or $f 2$; $g$ ray) were interleaved with rare and irregular tones (Oddballs; black) of the other frequency. Use of $f 1$ and $f 2$ as standard or oddball tones was swapped between stimulation blocks. For analysis, oddball-evoked responses (Odd) are compared with responses evoked by pre-oddball standard tones (PreOdd) and those by the first standard tone of each block (First). B, A1 was located using red-light intrinsic optical imaging. Left, Example image of exposed cortical surface. Right, Localized tissue reflectance decreases upon presentation of pure tones (8 kHz). C, Example images of an excitatory pyramidal neuron and tdTomato-expressing SST and PV interneurons (left to right) filled with AlexaFluor-488 (green) via whole-cell recording pipettes. $D$, Pooled data for average membrane potential $\left(V_{\mathrm{m}}\right)$, input resistance $\left(R_{\text {in }}\right)$, and AP half-width for the three cell types ( $n=21,20$, and 11 for Exc, SST, and PV neurons). E, Example $V_{\mathrm{m}}$ responses in Exc, SST, and PV cells evoked by tones of their respective BFs (Exc: 11.3 kHz; SST: 26.9 kHz; PV: $11.3 \mathrm{kHz}$ ). Top row, Individual (gray) and average (colored) traces of the original $V_{\mathrm{m}}$ responses. Middle row, Estimated subthreshold $V_{\mathrm{m}}$ obtained by removing APs with median filtering. Bottom row, Colored lines show the average of the corresponding FRand the colored shades their SD. $F$, Comparisons of the BF-evoked peak $V_{\mathrm{m}}$ amplitudes $\left(\Delta V_{\mathrm{m}}\right)$ and maximum FR changes $(\Delta \mathrm{FR})$ during $100 \mathrm{~ms}$ after tone onsets between Exc $(n=22)$, SST $(n=$ 17), and PV cells $(n=11) \cdot \boldsymbol{D}, F$, Open circles indicate responses from individual neurons, and bold lines with error bars represent mean \pm SEM. ${ }^{* *} p<0.01,{ }^{*} p<0.05$. 
We quantified the differences in responses to oddballs and pre-oddball standards using a D-prime index for SSA defined as follows:

$$
d_{\text {SSA }}^{\prime}=\frac{\mu_{\text {odd }}-\mu_{\text {PreOdd }}}{\sqrt{\frac{1}{2}\left(\sigma_{\text {odd }}^{2}+\sigma_{\text {PreOdd }}^{2}\right)}},
$$

where $\mu$ and $\sigma$ denote the mean and SD of the response amplitudes to oddballs (Odd) and pre-oddball standards (PreOdd), applied to either early or late time window. A positive value for $d^{\prime}{ }_{S S A}$ indicates stronger responses for the oddball tone. In previous SSA studies, common selectivity indices (CSI) based on the differences between oddball and standard responses and normalized by the overall activity level for both $f_{1}$ and $f_{2}$ have been used for quantifying the SSA magnitude (Ulanovsky et al., 2003; von der Behrens et al., 2009; Taaseh et al., 2011; Hershenhoren et al., 2014). CSI was computed as follows:

$$
\mathrm{CSI}=\frac{\left(\mu_{\mathrm{Odd}, f 1}+\mu_{\mathrm{Odd}, f 1}\right)-\left(\mu_{\mathrm{Sta}, f 1}+\mu_{\mathrm{Sta}, f 2}\right)}{\left(\mu_{\mathrm{Odd}, f 1}+\mu_{\mathrm{Odd}, f 1}\right)+\left(\mu_{\mathrm{Sta}, f 1}+\mu_{\mathrm{Sta}, f 2}\right)},
$$

where $\mu_{\text {Odd }, f 1}, \mu_{\text {Odd }, f 2}$ and $\mu_{\text {Sta } f 1}, \mu_{\text {Sta }, f 2}$ represent the mean $V_{\mathrm{m}}$ amplitude or mean FR change evoked by oddball and pre-oddball standard tones for $f_{1}$ or $f_{2}$ frequency. Compared with $d^{\prime}{ }_{\text {SSA }}$, CSI is susceptible to low activity levels such as the sparse firing in L2/3 excitatory cells, as well as the small amplitudes of the late response components, thus giving rise to more boundary values $(0,1)$ and larger within-group variation. Given the wide spectrum of response levels in A1 cell, $d^{\prime}{ }_{\text {SSA }}$ is therefore more suitable for the present study to quantify SSA.

To investigate the frequency preference effect on SSA, preferred and nonpreferred frequencies were defined by calculating the $d^{\prime}$ Pref index derived from the peak $V_{\mathrm{m}}$ amplitudes evoked by the first standard tones as follows:

$$
d_{\text {Pref }}^{\prime}=\frac{\mu_{f 1}-\mu_{f 2}}{\sqrt{\frac{1}{2}\left(\sigma_{f 1}^{2}+\sigma_{f 2}^{2}\right)}},
$$

where $\mu$ and $\sigma$ are the mean and SD for the first tone-evoked responses to respective frequencies, $f 1$ and $f 2$. For $d_{\text {Pref }}^{\prime}>0, f 1$ is the preferred frequency, and for $d^{\prime}$ Pref $<0, f 2$ is the preferred frequency.

Classification analysis was performed with a probabilistic Bayesian Classifier, as implemented in MATLAB Statistics toolbox (NaïveBayes class). Membrane potential recordings were down-sampled to $200 \mathrm{~Hz}$ and a $50 \mathrm{~ms}$ sliding window was used (10 data points per classification step). Cross-validation was performed by leaving out $20 \%$ of the trials per iteration and testing classifier performance on the left-out data. Average classifier performance was determined as mean over 120 iterations.

Statistical comparisons involving different neurons (e.g., between cell types or control vs MK-801) were performed as unpaired $t$ tests and comparisons between conditions (e.g., oddball vs standard) as paired $t$ tests. In all statistical procedures involving multiple comparisons, comparison results were accordingly adjusted using Bonferroni correction.

\section{Results}

\section{Whole-cell recordings of tone-evoked responses in different neuronal cell types in A1}

We obtained two-photon-targeted whole-cell recordings from L2/3 SST and PV interneurons in identified A1 of isofluraneanesthetized SST $\times$ tdTomato and $\mathrm{PV} \times \mathrm{tdTomato}$ mice, respectively (Fig. $1 A-C$ ). In addition, we recorded from unlabeled excitatory L2/3 pyramidal neurons (Exc) using the "shadowpatch" technique (Kitamura et al., 2008). The three cell types differed in basic electrophysiological properties such as resting membrane potential, input resistance, AP shape, and spontaneous firing rates (Fig. 1; Table 1), consistent with previous reports on L2/3 neurons (Gentet et al., 2012; Li et al., 2014). We stimulated L2/3 neurons with $100 \mathrm{~ms}$ pure tones of different sound frequencies (range $4-40 \mathrm{kHz}$ ), evoking membrane potential $\left(V_{\mathrm{m}}\right)$ changes and incidental APs on top of ongoing spontaneous
$V_{\mathrm{m}}$ fluctuations (Fig. 1D). For each neuron we measured a tuning curve and determined the $\mathrm{BF}$ at $80 \mathrm{~dB}$, i.e., the sound frequency eliciting the largest response. In all three neuron types we observed clear BF-evoked subthreshold $V_{\mathrm{m}}$ changes (Fig. 1E; APs removed by median filtering). Sound-evoked $V_{\mathrm{m}}$ responses were significantly larger in Exc and PV neurons compared with SST neurons and induced increases in FR, especially in the inhibitory interneurons but less frequently in pyramidal neurons (Fig. $1 E, F)$. BF evoked responses with short onset latency for $V_{\mathrm{m}}$ and FR changes $\left(30.8 \pm 3.4,34.6 \pm 4.5,22.4 \pm 3.5 \mathrm{~ms}\right.$ for $\mathrm{V}_{\mathrm{m}}$, and $31.9 \pm 5.1,24.1 \pm 1.9,27.1 \pm 9.0 \mathrm{~ms}$ for FR changes with $0.5 \mathrm{~ms}$ bin in Exc, SST, and PV cell, mean \pm SEM, $n=22,17$, and 11 , respectively; $p>0.1$ for $V_{\mathrm{m}}$ and $\mathrm{FR}$, one-way ANOVA). We did not observe slower onsets of SST cells compared with Exc and PV neurons as has recently been reported (Li et al., 2014), probably because of the fewer trials in the current study that leads to larger baseline variation. For each neuron we selected two appropriate frequencies below and above the BF to measure neuronal activity upon oddball paradigm stimulation (Fig. 1A).

\section{Response adaptation during repeated tone sequences}

We first analyzed how neuronal responses adapt to repeated standard tone presentation by averaging across the initial block of trials, during which standard tones were repeated for at least six times. The first stimulus evoked a fast and brief $V_{\mathrm{m}}$ depolarization, which caused transient increases in FR in all three cell types (Fig. $2 A, B ; V_{\mathrm{m}}$ peak latency from tone onset: Exc, $53.4 \pm 30.0 \mathrm{~ms}$, $n=20$; SST, $42.1 \pm 23.9 \mathrm{~ms}, n=20$; PV, $57.1 \pm 33.2 \mathrm{~ms}, n=12$; mean $\pm \mathrm{SD})$. In the majority of recordings the first tone also evoked a secondary longer-lasting $V_{\mathrm{m}}$ depolarization, most prominently in Exc and PV neurons, that initiated after tone offset and could last for several-hundred milliseconds (onset latency of inflection point from tone onset: Exc, $230 \pm 57 \mathrm{~ms}$; SST, $234 \pm 34 \mathrm{~ms}$; PV, $208 \pm 17 \mathrm{~ms}$; mean $\pm \mathrm{SD}$; proportion of cells with clear late component used in this analysis: 17/20, 8/20, 8/12 for Exc, SST, and PV neurons). The late depolarization caused FR increases particularly in PV neurons but not in Exc neurons, which remained mostly silent after the initial response. Similar stimulus-evoked, UP-state-like delayed response components in A1 have been reported in other studies (Metherate and Cruikshank, 1999; Grienberger et al., 2012).

Responses to the second tone and subsequent tones displayed pronounced adaptation of both early and late component. In the early time window, both $V_{\mathrm{m}}$ and FR response amplitudes were significantly reduced in all cell types already for the second tone, with the exception of FR in PV neurons, which showed less adaptation (Fig. 2C,D). For the sixth tone repetition, early $\mathrm{V}_{\mathrm{m}}$ response amplitudes reached a steady-state level of 30-50\% of the first-tone response ( $44 \pm 59 \%, 45 \pm 46 \%, 30 \pm 40 \%$ for Exc, SST, and PV neurons; mean $\pm \mathrm{SD}$ ). The late $V_{\mathrm{m}}$ response component also significantly adapted in Exc and PV neurons, but less so in SST neurons (Fig. 2C). FR changes during the late component adapted significantly in SST and PV interneurons, but not in pyramidal neurons, which seldom fired during the late phase (Fig. 2D). Notably, the adapted FR activity in PV cells upon repeated tone stimulation is higher than those in Exc and SST cells. These results show that the early tone-evoked responses rapidly adapt to repetitive tone presentation in all three cell types. In addition, the late component observed mainly in Exc and PV neurons also exhibits adaptation. 
A

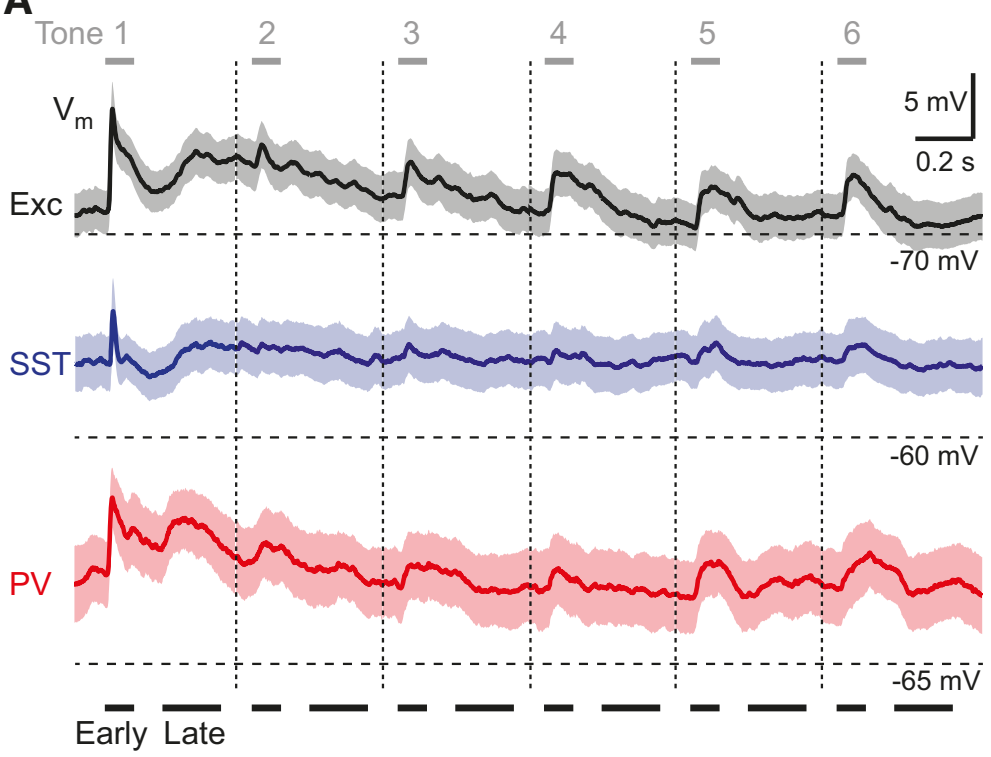

B

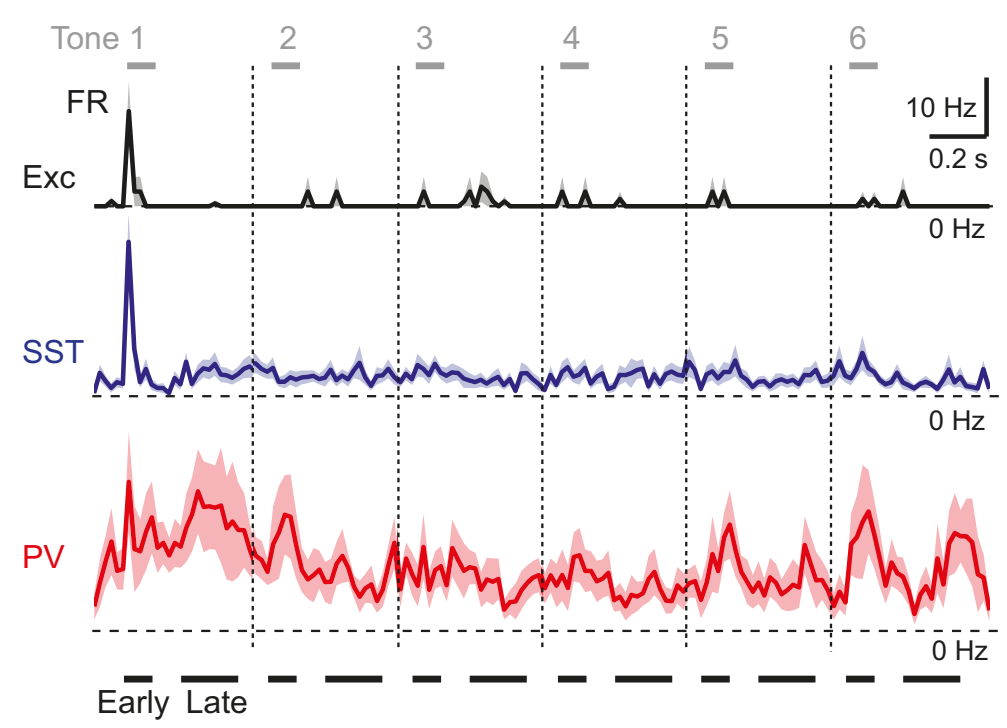

C
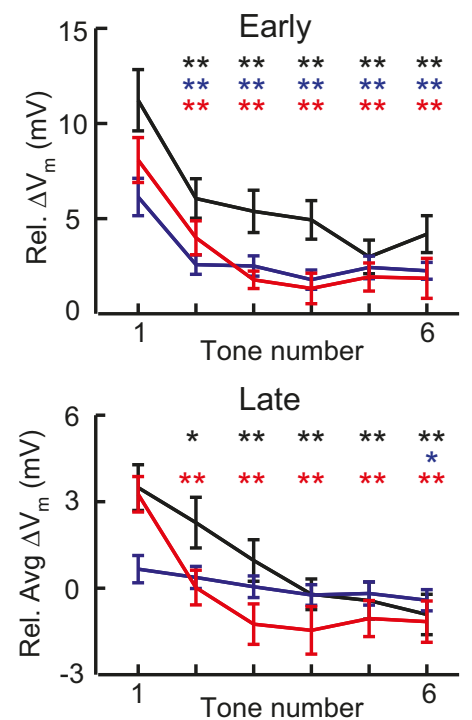

D
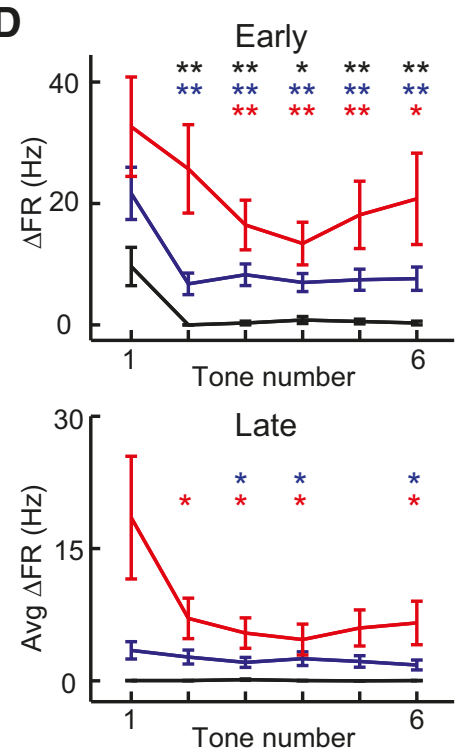

Figure 2. Neuronal adaptation during repeated standard tone presentation. $A$, Mean of filtered $V_{\mathrm{m}}$ responses for Exc, SST, and PV neurons for repeated stimulation with the same tone (colored average traces with shaded SEM range; responses were averaged from the initial 6 consecutive standard tone presentations during the oddball paradigm with $P_{0 \mathrm{dd}}=0.1, n=20,20,12$ for Exc, $S S T$, and PV cells). Early and late time windows for analysis are indicated as black bars below voltage traces $(0-0.1 \mathrm{~s}$ and $0.2-0.4 \mathrm{~s}$ after tone onset, respectively). Gray bars indicate tone durations. $\boldsymbol{B}$, Equivalent mean of FR responses, showing rapid adaptation of Exc and SST neurons and a more gradual response decrease in PV neurons. $C$, Changes in $V_{m}$ amplitude (mean \pm SEM) as a function of tone number in the series of six tones. Peak and mean amplitudes, relative to baseline before the first tone, were analyzed for early (top) and late (bottom) time window, respectively. Note that baseline $V_{m}$ for PV neurons was elevated due to spontaneous activity. $D$, FR changes as a function of tone number. Peak and mean amplitude of FR were quantified in early and late time window, respectively. Asterisks indicate significance of paired $t$ test comparisons between responses evoked by the $n$th and the first tone. ${ }^{* *} p<0.01$ and ${ }^{*} p<0.05$.

\section{Recovery of early and late responses from adaptation upon oddball tone stimulation}

We next examined how distinct A1 neuronal subtypes respond to a rare and irregular deviant tone using an oddball paradigm. We presented a series of repeating standard tones, interleaved with infrequent oddball tones of a different frequency. The two frequencies were chosen flanking each neuron's BF and oddballs were delivered with a probability of $P_{\text {Odd }}=0.1$, switching frequencies for standard and deviant across trial blocks (Fig. 1A). For all cell types, oddballs evoked enlarged early $V_{\mathrm{m}}$ responses compared with the adapted responses to pre-oddball standards (Fig. $3 A, B$ ). Oddballs frequently elicited APs in SST and PV neurons but seldom in pyramidal cells
(Fig. 3C,D). Furthermore, oddball tones also recovered the late component of the $V_{\mathrm{m}}$ responses, most obvious in Exc and PV neurons but less clear in SST neurons. The late oddballevoked $V_{\mathrm{m}}$ response remained subthreshold in Exc neurons and evoked extra APs only in PV cells.

We quantified the oddball effect by comparing the amplitude of early and late $V_{\mathrm{m}}$ responses for pre-oddball and oddball stimuli as well as for the first standard stimulus in trial blocks. Early $V_{\mathrm{m}}$ peak amplitudes were significantly enhanced for oddball compared with pre-oddball stimuli for all cell types (Fig. 3E; by a factor of 3.7, 3.1, and 3.7 for Exc, SST, and PV neurons, respectively; $p<0.01 ; n=20,20,12)$. For the late component a significant fourfold to fivefold enhancement of the mean $V_{\mathrm{m}}$ 

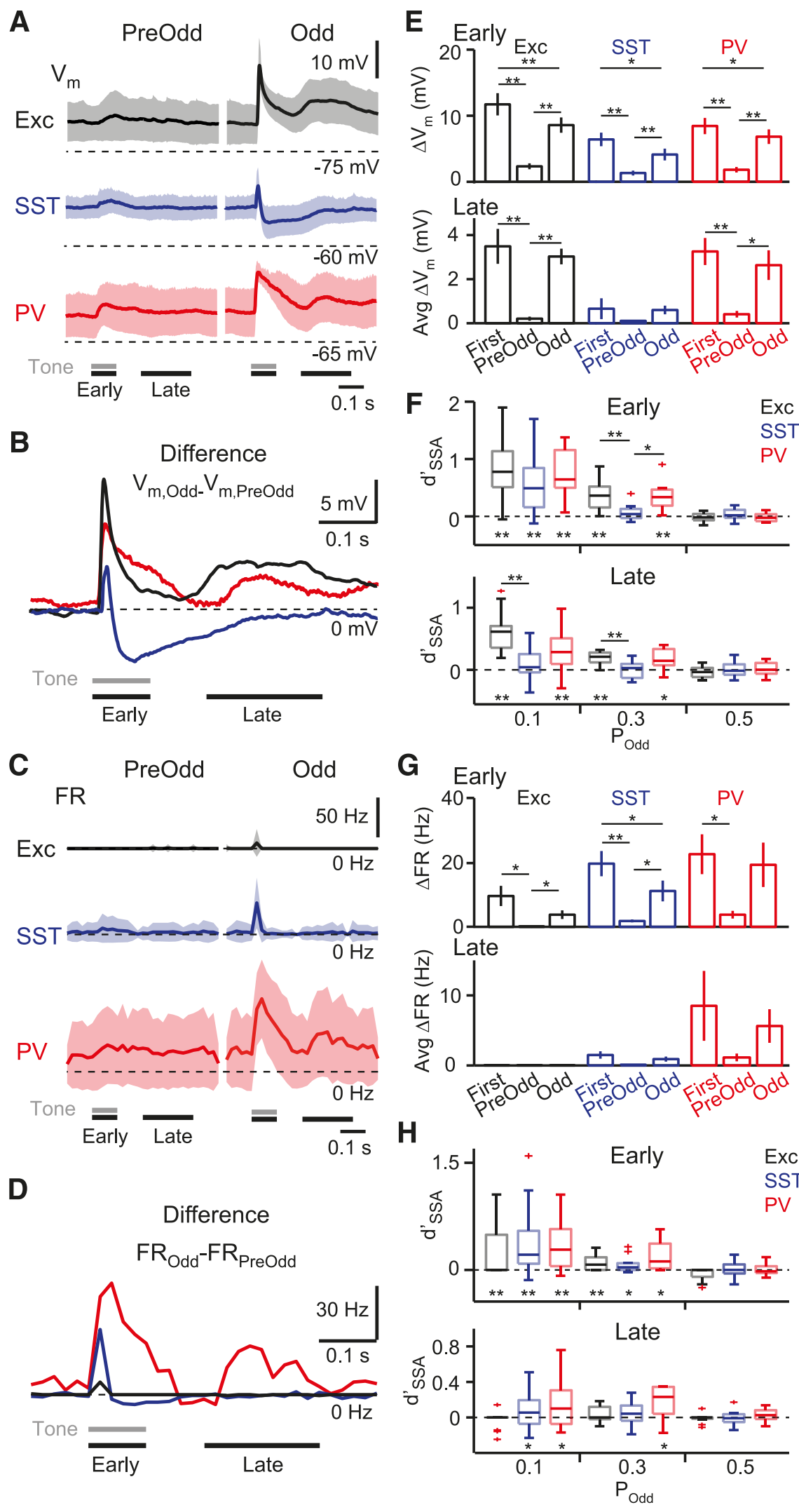

Figure 3. Oddball tones recover subthreshold and spiking responses of $A 1$ neurons. $A$, Subthreshold $V_{m}$ responses (mean $\pm S D$ ) to pre-oddball standard (Pre0dd; left) and oddball (Odd; right) tones for exemplary Exc, SST, and PV neurons with $P_{\text {Odd }}=0.1 . B$, Difference traces for the three example neurons shown in $A$. Peak amplitude within the early time window and mean amplitude during the late time window were computed for analysis. $C, D$, Corresponding mean FR changes $( \pm S D)$ and $F R$ difference traces for the same cells shown in $A . E$, Peak $V_{\mathrm{m}}$ response amplitude $\left(\Delta V_{\mathrm{m}}\right)$ for the first standard tone (First), the pre-oddball standard and the oddball tone for the early (top) and late (bottom) time windows for all Exc, SST, and PV neurons. F, Box plot comparison of the amplitude was observed for Exc and PV neurons $(p<0.05$, paired $t$ test $)$. Despite this enhancement, oddball $V_{\mathrm{m}}$ responses were, however, generally $\sim 20-35 \%$ smaller than the responses to the first stimulus. Our finding is consistent with a synaptic mechanism underlying SSA, with deviant tones recovering neuronal activity by recruiting distinct, largely nonadapted afferent pathways together with afferents partially overlapping with those adapted by the standard tone.

We also analyzed the selectivity of responses for oddballs versus pre-oddball standards for either early or late time window using a $d^{\prime}$ index for SSA $\left(d^{\prime}{ }_{\text {SSA }}\right)$. This analysis confirmed that oddball tones $\left(P_{\text {Odd }}=0.1\right)$ induced significantly enlarged $V_{\mathrm{m}}$ depolarization in both early and late phase for all neuronal types (Fig. 3F; $p<$ 0.01 , one-sample right-tailed $t$ test against $d_{\text {SSA }}^{\prime}=0$ ). The same analysis for control experiments with higher $P_{\text {Odd }}$ values of 0.3 and 0.5 revealed that SSA magnitude depends on the rarity of the oddball stimulus and that it is absent for equal probability of oddball and standards. For SST neurons $d^{\prime}$ SSA was not significantly different from zero at $P_{\text {Odd }}=0.3$ and SSA generally was less pronounced compared with Exc and PV neurons. Such dependence of SSA magnitudes on oddball probability is as well reflected in the difference traces based on grand average $V_{\mathrm{m}}$ (oddball - pre-oddball standard), whose peak derivatives indicate the onsets of early and late responses (Fig. 4). By taking the first derivative of the difference traces, onsets of early and late $V_{\mathrm{m}}$ responses can be estimated as the latency of the first and the second local maximum respectively (early onsets, $P_{\text {Odd }}=0.1: 23,22$, and $24 \mathrm{~ms}$ for Exc, SST, and PV cells: $P_{\text {Odd }}=$ $0.3: 26,26$, and $23 \mathrm{~ms}$ for the respective three cell types; late onsets, $P_{\text {Odd }}=0.1: 212$ and

$\leftarrow$

adaptation index $\left(d^{\prime}{ }_{\text {SSA }}\right)$, calculated for $V_{m}$ depolarization in early (top) and late (bottom) time windows, across cell types and for three different oddball probabilities. G, Mean FR change $(\Delta F R)$ for first, pre-oddball, and oddball stimuli in early (top) and late (bottom) time windows for all Exc, SST, and PV neurons. $\boldsymbol{H}$, Comparison of $d^{\prime}{ }_{S S A}$, calculated for FR change in early (top) and late (bottom) time windows, across cell types and for three different oddball probabilities. For $\boldsymbol{E}$ and $\boldsymbol{G}$, bars and error bars represent mean \pm SEM, with asterisks indicating statistical significance of two-sample comparisons between stimulus types. For $\boldsymbol{F}$ and $\boldsymbol{H}$, top and bottom edges of boxes represent the first and third quartiles, and the middle line the median. Whiskers indicate 1.5 interquartile range and outliers are shown as red crosses. Top asterisks indicate outcome of one-sample right-tailed $t$ test against the null hypothesis $d_{\text {SSA }}^{\prime}=0$. Bottom asterisks indicate statistical significance of two-sample comparisons between cell types. ${ }^{* *} p<0.01,{ }^{*} p<0.05$. 


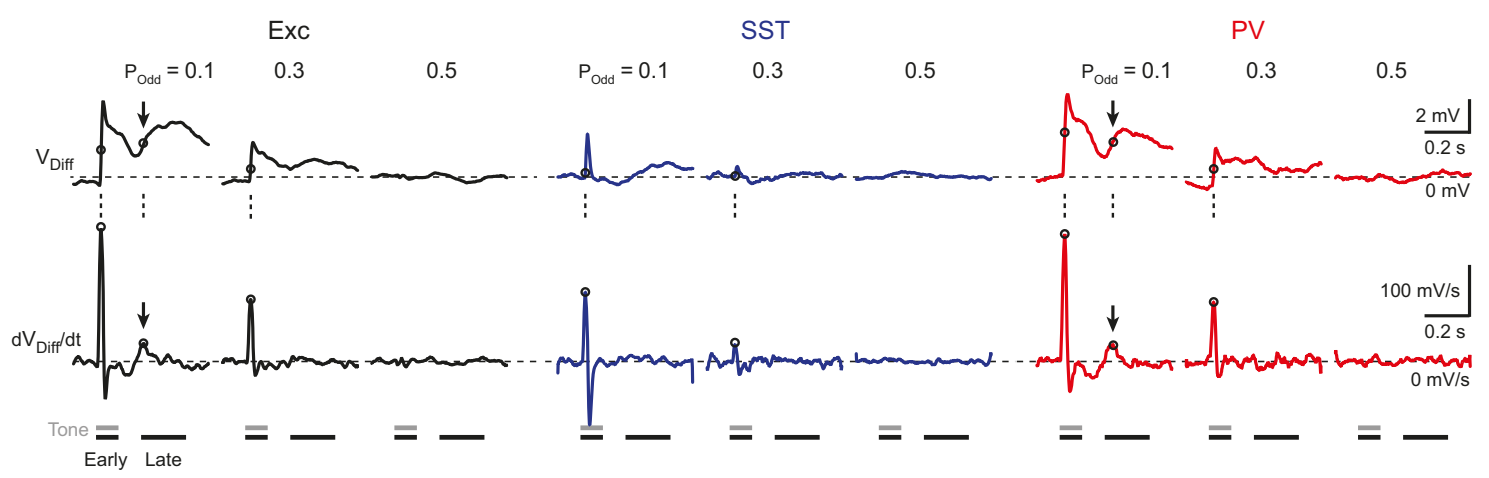

Figure 4. Difference waveform depends on oddball probability and can be used to estimate response onsets. Traces in the top row show the difference traces $\left(V_{\text {Diff }}\right)$ of mean oddball-evoked $V_{\mathrm{m}}$ response minus mean pre-oddball evoked $V_{\mathrm{m}}$ response for $P_{\text {Odd }}=0.1,0.3$, and 0.5 in the three cell types (grand averages from $n=20,20$, and 12 for Exc, SST, and PV cells, respectively). The corresponding first derivatives of the difference traces ( $d V_{\text {Diff }} d d$; smoothed by a moving average filter of $19 \mathrm{~ms}$ span at $1 \mathrm{kHz}$ sampling rate) are shown in the bottom row. The onsets of the early responses can be estimated as the latency of the initial peaks of the first derivatives for $P_{\text {Odd }}=0.1$ and 0.3 in all three neuronal types. The second local maxima of the first derivative, which are most prominent for $P_{\text {0dd }}=0.1$ in Exc and PV cells, specify the onsets of the late components. Gray bars indicate tone duration and black bars the early and late time windows.

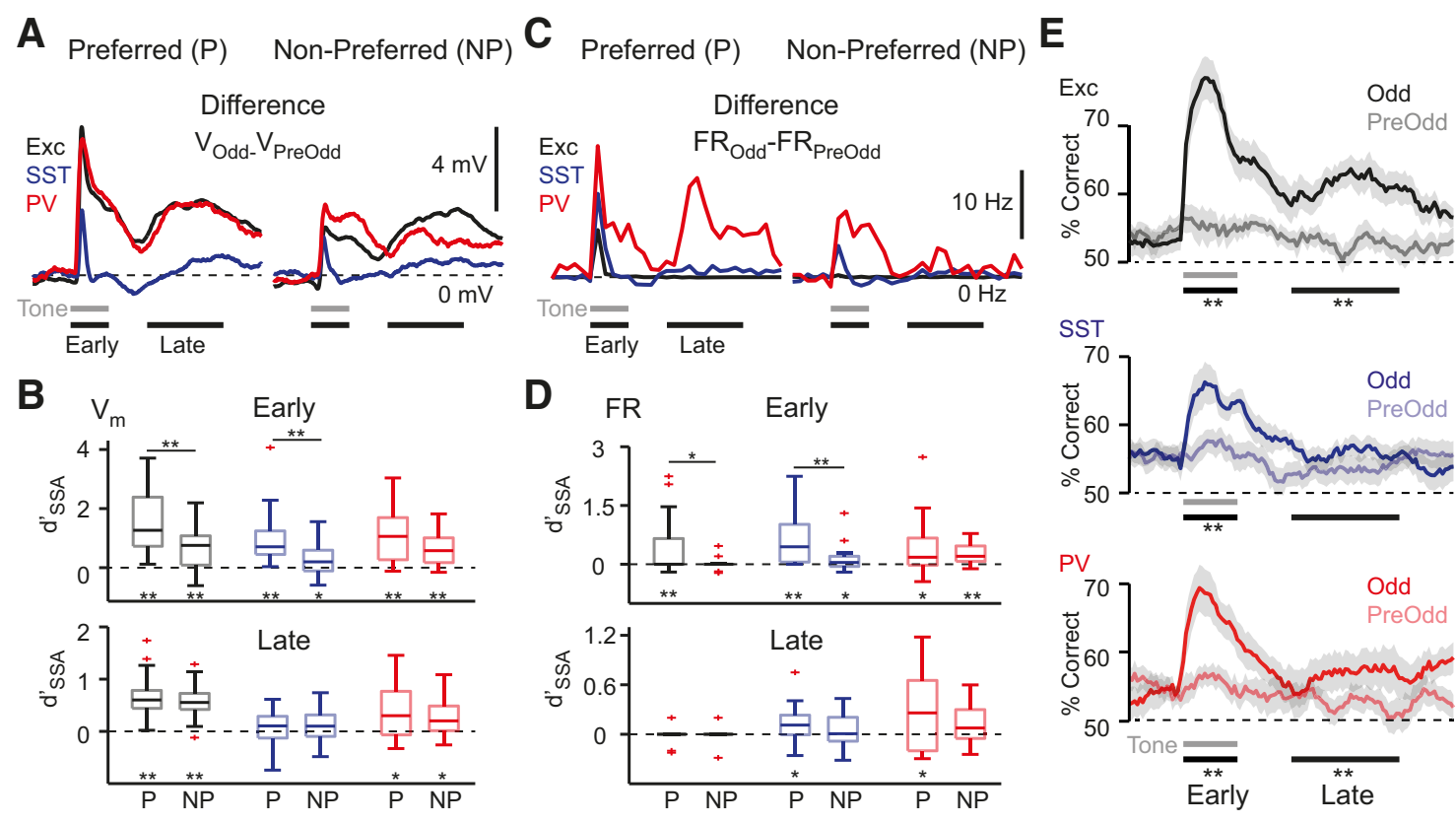

Figure 5. Cell-type-specific modulation of oddball tone responses by frequency preference. $A$, Grand average wave forms for oddball minus pre-oddball difference of the $V_{\mathrm{m}}$ changes evoked when oddball frequency matched the neuron's preferred (left) of nonpreferred (right) frequency. Gray bars indicate tone duration. Black bars represent the early and late component time windows. $\boldsymbol{B}$, Comparisons of SSA index $d^{\prime}{ }_{S S A}$ for $V_{m}$ changes in response to oddballs of preferred (P) and nonpreferred (NP) frequency within early and late time windows. Boxplots were calculated as in Figure 3. C, $\boldsymbol{D}$, Same as $\boldsymbol{A}$ and $\boldsymbol{B}$, but for $F R$ changes. $\boldsymbol{E}$, Discriminability of tone frequency ( $f 1$ vs $f 2$ ) for oddball compared with pre-oddball standard tones. Traces show averaged binned classification performance of a Bayesian classifier on $V_{\mathrm{m}}$ responses. Chance performance is $50 \%$. Stars indicate significance of $0 \mathrm{dd}$ versus Pre0dd classification difference over the respective time windows (two-way repeated-measures ANOVA). ${ }^{* *} p<0.01{ }^{*} p<0.05$.

$237 \mathrm{~ms}$ for Exc and PV cells). In addition, we quantified the oddball effect with an alternate definition of SSA index, CSI (Hershenhoren et al., 2014). For the subthreshold $V_{\mathrm{m}}$ responses, the comparison results derived from CSI were similar to those from $d^{\prime}$ index (CSI of early $V_{\mathrm{m}} 0.56 \pm 0.06,0.49 \pm 0.08,0.58 \pm 0.07$ in Exc, SST, and PV cells and late $V_{\mathrm{m}} 0.89 \pm 0.04,0.19 \pm 0.16,0.58 \pm 0.18$, mean $\pm \mathrm{SEM}$, $n=20,20$, and 12 , respectively). We nevertheless found that CSI is susceptible to low activity level such as the sparse spiking activity for L2/3 pyramidal neurons in A1 and the relatively small evoked responses within the late time window (CSI for early FR $0.39 \pm 0.11$, $0.58 \pm 0.10,0.47 \pm 0.14$ and late $\mathrm{V}_{\mathrm{m}}-0.10 \pm 0.10,0.24 \pm 0.17$, $0.20 \pm 0.22$ for Exc, SST, and PV cells, mean \pm SEM). Small changes under low baseline activity levels would lead to artificially large SI values. In the present study, we therefore preferred to use $d^{\prime}$ instead of SI because the $d^{\prime}$ index provides a robust measure of selectivity over a wide range of activity levels in A1 neurons.

The analogous quantitative analysis for oddball-evoked FR changes revealed that the recovered early depolarization consistently increased peak FR in the early time window (Fig. 3G; significant increase for oddball vs pre-oddball response for Exc and SST neurons, $p<0.05$, paired $t$ test; approaching significance for PV neurons that showed higher variability in spiking, $p<0.1$ ). Consistent with the subthreshold responses, the FR changes recovered by the oddball remained smaller than the FR activity evoked by the first standard tones. For the late component, only PV neurons displayed enhanced FR levels upon oddball stimulation, which did not however reach statistical significance (Fig. $3 G)$. For Exc neurons, no extra APs were elicited during the late 
time window. Hence, the late component was visible only in the subthreshold regime, presumably reflecting enhanced synaptic input activity upon oddball stimulation during this period. In all three cell types, $d^{\prime}{ }_{\text {SSA }}$ values calculated for the early FR changes revealed significant SSA for $P_{\text {Odd }}=0.1$ and 0.3 , but not for $P_{\text {Odd }}=0.5$. For the late response window, $d^{\prime}$ SSA values were just significantly larger from zero only for the GABAergic interneurons at low oddball probability (Fig. $3 H$ ). We conclude that SSA is present in mouse auditory cortex not only in excitatory neurons but also in two major classes of cortical GABAergic interneurons (SST and PV neurons). In addition to the early tone-evoked responses exhibiting SSA, our whole-cell recording method reveals that a rare and irregular oddball tone recovers the subthreshold late components as well.

\section{Dependence of oddball-evoked responses on frequency preference}

As A1 neurons typically responded asymmetrically to the two frequencies used in the oddball paradigm (Fig. $1 A$ ), we next explored how SSA is influenced by tuning preferences for the presented tones. We defined "preferred" and "nonpreferred" frequencies according to which tone frequency resulted in a larger mean $V_{\mathrm{m}}$ response to the first standard tone. Both preferred and nonpreferred oddball tones displayed significant SSA (i.e., $d_{\text {SSA }}^{\prime}>0$ ) for early $V_{\mathrm{m}}$ and FR responses (Fig. $5 B, D$; $p<$ 0.05 for all cell types except for early FR evoked by nonpreferred oddballs in Exc, right-sided paired $t$ test against zero). Nevertheless, preferred oddball tones evoked larger early $V_{\mathrm{m}}$ responses and displayed more prominent SSA (Fig. $5 A, B ; p<0.01$ for Exc and SST, $p>0.1$ for PV, paired $t$ test of $d^{\prime}{ }_{\text {SSA }}$ between preferred and nonpreferred oddballs). The frequency preference was also reflected in larger early FR changes evoked by preferred oddball tones (Fig. $5 C, D ; p<0.05$ for Exc and SST, $p>0.1$ for PV, paired $t$ test). The oddball-evoked late $V_{\mathrm{m}}$ responses, on the other hand, exhibited significant SSA for Exc and PV cells (Fig. 5B; $p<$ 0.05 for Exc and PV, right-sided paired $t$ test of $d^{\prime}$ SSA against zero) but without frequency preference $(p>0.05$ for all cell types, paired $t$ test of $d^{\prime}$ SSA between preferred and nonpreferred oddballs). For late spiking activity, significant SSA was found in PV and SST only for preferred oddballs (Fig. 5D). These results indicate that SSA is not homogeneous across the receptive field (Duque et al., 2012), and that gain mechanisms, such as activation of different amounts of inputs or recruitment of local recurrent subnetworks, exert a modulatory effect on SSA.

We next investigated how stimulus context (lowprobability tone violating the preceding regularity) affects the frequency discrimination power of auditory neurons. We trained a probabilistic Bayesian classifier to distinguish between the two frequencies $\left(f_{1}\right.$ and $\left.f_{2}\right)$ based on $V_{\mathrm{m}}$ responses to pre-oddball standard and oddball tones. The classifier discriminated frequencies above chance $(50 \%)$ under both tone conditions (Fig. 5E). Nevertheless, classification accuracy during the early component was significantly better for oddball tones in all cell types (Fig. 5E; oddball vs pre-oddball: $p<0.01$ for all cell types, two-way repeated-measures ANOVA). During the late component, in contrast, frequency discrimination differed between oddball and standard tones in a cell-typespecific manner, with PV and Exc showing enhanced discrimination (Fig. $5 E$; oddball vs pre-oddball: $p<0.01$, two-way repeated-measures ANOVA), whereas no difference was observed for SST interneurons $(p>0.1$, two-way repeatedmeasures ANOVA). In summary, our results demonstrate that responses to low-probability tones are modulated by sound

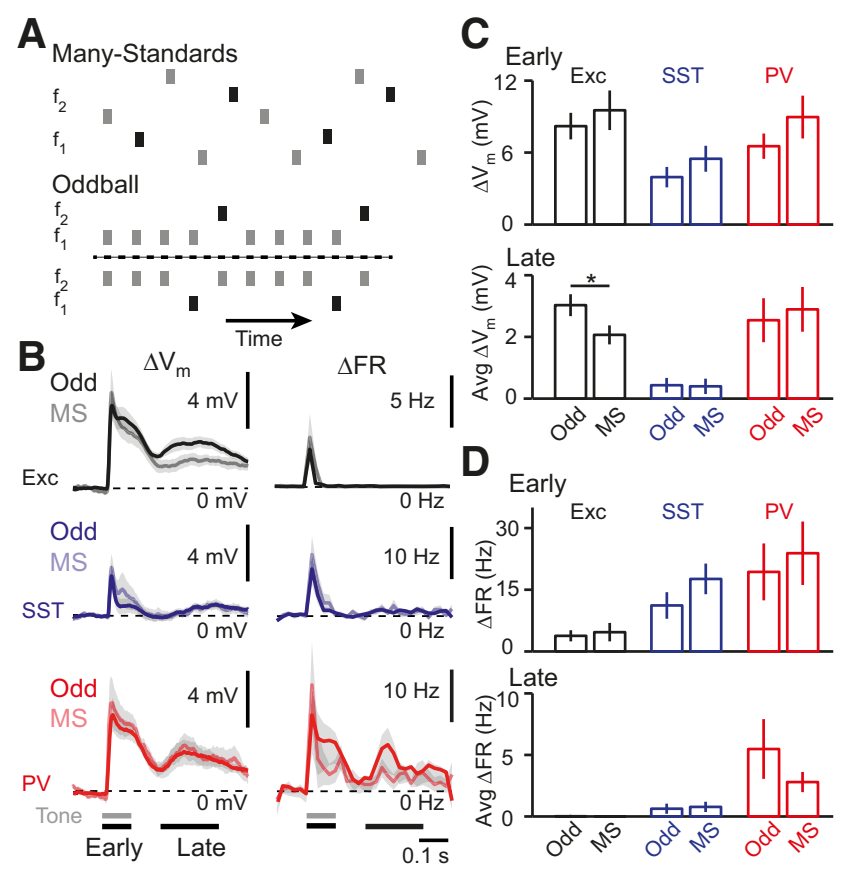

Figure 6. Subthreshold late oddball-response component carries signs of deviance detection. $\boldsymbol{A}$, Schematic illustration of the relation between MS and oddball paradigm. In the MS condition, tones of frequencies $f 1$ and $f 2$ are presented within a pseudo-random sequence of tones of 15 different frequencies. Compared with the oddball condition, no regularity is established. Increased activity to oddballs compared with the same frequency tones in MS condition (MS tones) could indicate genuine deviance detection. $\boldsymbol{B}$, Grand average $V_{\mathrm{m}}$ amplitudes and FR changes (both relative to baseline activity before each tone) for oddball (0dd; $\left.P_{0 \mathrm{dd}}=0.1\right)$ and MS tones. Average responses are shown as colored lines and the SEM across each subpopulation as gray shades. Tone duration ( $0.1 \mathrm{~s}$ for both oddball and MS tones) is indicated as gray bars below traces and early and late time windows as black bars. $C, D$, Comparisons of peak $V_{m}$ amplitudes $(\boldsymbol{C})$ and $F R$ changes $(\boldsymbol{D})$ evoked by oddball and MS tones within early and late time windows. Bar graph indicates the averages and error bars indicate 1 SEM. ${ }^{*} p<0.05$.

frequency and, conversely, that frequency discrimination is influenced by tone probability, most interestingly in a celltype-specific manner within the late time window.

\section{The late oddball-evoked response may reflect genuine deviance detection}

The classic frequency oddball paradigm (Fig. $1 A$ ) does not, on its own, allow distinction between SSA and genuine deviance detection (Nelken and Ulanovsky, 2007; Taaseh et al., 2011; Fishman and Steinschneider, 2012). The latter is considered a higher-level process involving detection of disruptions in an auditory sequence (Näätänen et al., 2005). To address the distinction between SSA and deviance detection, we compared oddball tone responses with the activity evoked by tones of the same frequency in the random tone sequence, which was used to determine the $\mathrm{BF}$ for each neuron (Fig. 6A). In this many-standards (MS) condition (Fishman and Steinschneider, 2012), no regularity is established because subsequent tones vary in an unpredictable fashion. If the increased responses to deviant tones in the oddball paradigm would be comparable with responses in the MS condition, this would indicate that the large deviant responses during oddball stimulation can be explained solely by SSA. On the other hand, if the oddball tones evoke larger responses than the same tones under MS stimulation, this would constitute evidence for true deviance detection (Fishman and Steinschneider, 2012). We found that, for all three cell types, initial tone-evoked subthreshold and spiking responses (early responses) were comparable for 

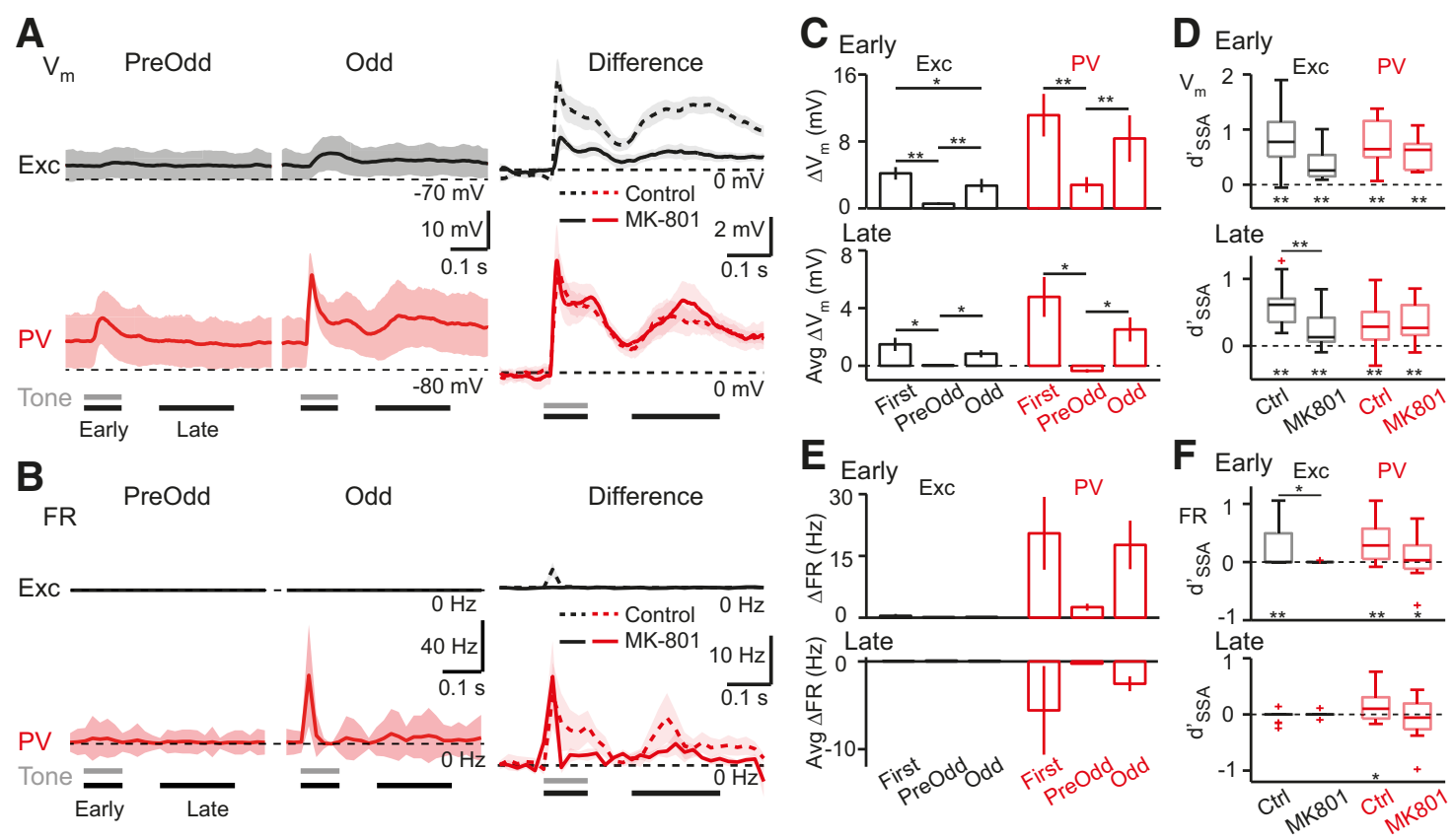

Figure 7. Oddball membrane potential responses are sensitive to NMDA receptor signaling in a cell-type-specific manner. $\boldsymbol{A}, \boldsymbol{B}$, Average $V_{\mathrm{m}}(\boldsymbol{A})$ and firing rate $(\boldsymbol{B})$ in response to pre-oddball standard (Pre0dd) and oddball (0dd; $\left.P_{0 \mathrm{dd}}=0.1\right)$ tones in example Exc and PV cells with intracellular infusion of NMDA-receptor antagonist MK-801. Colored lines are shown as the average responses and colored shades as the SD for each neuron. Right panels indicate the grand mean difference responses $\left(V_{\mathrm{m}}\right.$, FR; $0 \mathrm{ddball}$ - pre-oddball). Solid lines represent the grand average response with MK-801 blockage ( $n=11,9$ for Exc and PV cells), dashed lines those under control condition ( $n=20,12$ for Exc and PV cells, respectively); colored shades indicate SEM across the subpopulation of each cell type. Tone duration is shown as gray bars and early and late time windows as black bars below traces. Note that MK-801 application leads to a clearly reduced difference waveform for $V_{\mathrm{m}}$ and spiking activity in pyramidal neurons. $C$, Comparisons of peak $V_{\mathrm{m}}$ amplitudes evoked by the first, pre-oddball standard and oddball tones within early and late time windows under intracellular MK-801 infusion. D, Comparisons of $d^{\prime}$ sSA index computed from $V_{\mathrm{m}}$ between control condition and with MK-801 infusion for early and late responses. Data are shown with box plots as represented in Figure $3 F, H$. Lower stars indicate the outcome of one-sample right-tailed $t$ test against zero and upper stars represent the results of two-sample comparisons between control and MK-801 treatment. $\boldsymbol{E}, \boldsymbol{F}$, Same as $\boldsymbol{C}$ and $\boldsymbol{D}$ but for FR changes. ${ }^{* *} p<0.01,{ }^{*} p<0.05$.

oddball tones and corresponding tones in the MS condition (Fig. $6 B)$. Both peak $V_{\mathrm{m}}$ and FR did not differ significantly during the early phase after tone onset (Fig. $6 C, D$; oddball vs MS: all $p>$ 0.05 , paired $t$ tests). Interestingly, however, in pyramidal neurons the late $V_{\mathrm{m}}$ component was significantly more depolarized in response to the oddball tones compared with the MS condition (Fig. 6C; oddball vs MS: $p<0.05$, paired $t$ test). These results suggest that the late depolarization evoked by oddball tones in L2/3 pyramidal neurons may reflect deviance detection in primary auditory cortex.

\section{Auditory responses depend on NMDA receptor signaling in Exc but not PV neurons}

A key property of MMN is its dependence on NMDA-type glutamate receptor (NMDAR) signaling (Javitt et al., 1996; Umbricht et al., 2000), suggesting that nonlinear dendritic integration processes may play a role in deviance detection. To test whether NMDAR activation is involved in the responses evoked by oddball tones, we obtained additional whole-cell recordings in Exc $(n=11)$ and PV neurons $(n=9)$ and blocked NMDARs by intracellular infusion of the noncompetitive antagonist MK-801 (Lavzin et al., 2012). Unlike systemic application of NMDAR blockers that affects NMDAR signaling in the entire neuronal network (Tikhonravov et al., 2008; Farley et al., 2010), our intracellular approach blocks the NMDARmediated dendritic mechanisms only in the recorded cell. Intracellular MK-801 application clearly reduced evoked $V_{\mathrm{m}}$ responses in pyramidal neurons but not in PV interneurons (Fig. 7A). Spiking responses of pyramidal neurons to oddball tones were largely reduced, whereas FR changes were not affected in PV neurons (Fig. $7 B$ ). Oddball tones still evoked significantly larger $V_{\mathrm{m}}$ responses than standard tones during both early and late components (Fig. $7 C$; for Exc and PV, $p<0.01$ for early and $p<0.05$ for late, paired $t$ tests between tone types). However, compared with control condition, the overall decreased responses to oddballs, as well as to pre-oddball standards led to smaller SSA indices after MK-801 infusion, especially for the late time window (Fig. 7D; control vs MK-801: $p>0.1$ for Exc early and $p<0.01$ for late, two-sample $t$ tests between control and MK-801 conditions). By comparing oddball-evoked activity with MS control, such reduction in oddball-evoked late $V_{\mathrm{m}}$ in Exc cell after MK-801 blockade further results in absent deviance detection (Odd vs MS, $0.83 \pm 0.25$ vs $0.77 \pm 0.29 \mathrm{mV}$ for late $V_{\mathrm{m}}, p>$ 0.05 , two-sample $t$ test between Odd and MS). Comparisons between control and MK-801 conditions for $V_{\mathrm{m}}$ responses of PV neurons were not significantly different (Fig. $7 D ; p>0.1$ for PV early and late, two-sample $t$ test). Similar results were obtained for FR changes after MK-801 application (Fig. 7E). Notably, the selective early FR increase in Exc neurons in response to oddball tones was strongly suppressed by MK-801 (Fig. 7F; control vs MK-801: $p<$ 0.05 for Exc early and $p>0.1$ for late, two-sample $t$ test between control and MK-801). In contrast, FR responses of PV neurons were not influenced by MK-801 (Fig. 7F; $p>0.1$ for PV early and late, two-sample $t$ test). These findings suggest a possible link between macroscopic brain activity evoked by deviant stimuli and the corresponding membrane potential dynamics in defined neuronal cell types. They further suggest that frequencyand context-specific activation of pyramidal neurons in A1 may be achieved, at least partly, by NMDAR-mediated, active dendritic integration mechanisms (Gambino et al., 2014; Palmer et al., 2014), and may be required to trigger the secondary, longer-lasting late response component. 


\section{Discussion}

Recording membrane potential dynamics from genetically defined neuronal types provides critical information for understanding how cortical circuits process oddball stimuli that break a previously established regularity. Using two-photon-guided in vivo whole-cell recordings in mouse A1, we compared subthreshold and suprathreshold responses upon oddball stimulation in excitatory and inhibitory neurons. Our main findings are as follows: (1) we report two temporally distinct early and late response components that encode oddball tones in the studied cell types; (2) SSA is present in Exc neurons as well as in PV and SST interneurons, with oddball tones recovering both early and late response components compared with the preceding standards, suggesting that a large portion of A1 neurons adapts to repetitive stimuli, and then becomes reactivated through the synaptic drive recruited by a deviant stimulus; and (3) the late component, particularly in Exc cells, shares characteristics such as time course, deviance-encoding, and pharmacological properties with the MMN EEG signal component, and therefore may be the "missing link" between neuronal SSA and MMN.

\section{SSA is present in SST and PV interneurons}

We found that both SST and PV interneurons in A1 adapt to repeating standard tones (Fig. 2) and subsequently recover their activity when the oddball tone is presented (Fig. 3). Although subcortical SSA has been reported primarily in the nonlemniscal part of inferior colliculus (Malmierca et al., 2009; Ayala and Malmierca, 2012) and the medial geniculate body of thalamus (Anderson et al., 2009; Antunes et al., 2010), the prominent SSA seen in the lemniscal A1 in our study and previous studies (Ulanovsky et al., 2003; Hershenhoren et al., 2014) indicates de novo generation or amplification of SSA in cortical circuitry (Nelken, 2014). Two mechanisms may contribute to the recovered early responses evoked by oddballs. First, increased inhibition may build up during repeated presentation of standards and an oddball tone would release neuronal inhibition. This model is analogous to the earlier "disinhibition hypothesis" regarding MMN in tonopically organized A1 (Näätänen, 1984; Picton et al., 2000). Our results are inconsistent with this scenario as we found that SSA is present in both SST and PV interneurons. Rather, the similarity in the early oddball responses in excitatory and inhibitory neurons suggests overall excitation-inhibition balance during SSA (Wehr and Zador, 2003; Higley and Contreras, 2006), possibly through common synaptic mechanisms in the excitatory pathways of direct or indirect thalamocortical projections (Smith and Populin, 2001; Barbour and Callaway, 2008). Nonetheless, inhibition may participate in SSA in more subtle manners. For example, slower adaptation in the spiking activity of PV interneurons (Fig. 2) could contribute to the attenuation of standard-evoked activity (in Exc cells) during tone sequences (Pérez-González et al., 2012; Duque et al., 2014). In addition, different rates of recovery from adaptation between excitatory and inhibitory neurons could shape oddball responses (Malina et al., 2013). Finally, the rapid adaptation seen in SST interneurons (Fig. 2) may arise from inhibitory action of VIP-expressing interneurons (Pi et al., 2013), which were not studied here.

The alternative explanation for SSA is that repeating standard tones cause depression in a subset of activated excitatory inputs, and an oddball activates another subset of nonadapted synapses thus recovering the response amplitude (Fig. 8). This model is analogous to a more recent "adaptation hypothesis" of MMN in A1 (May et al., 1999; May and Tiitinen, 2010). Our results are more consistent with this model and indicate synaptic depression

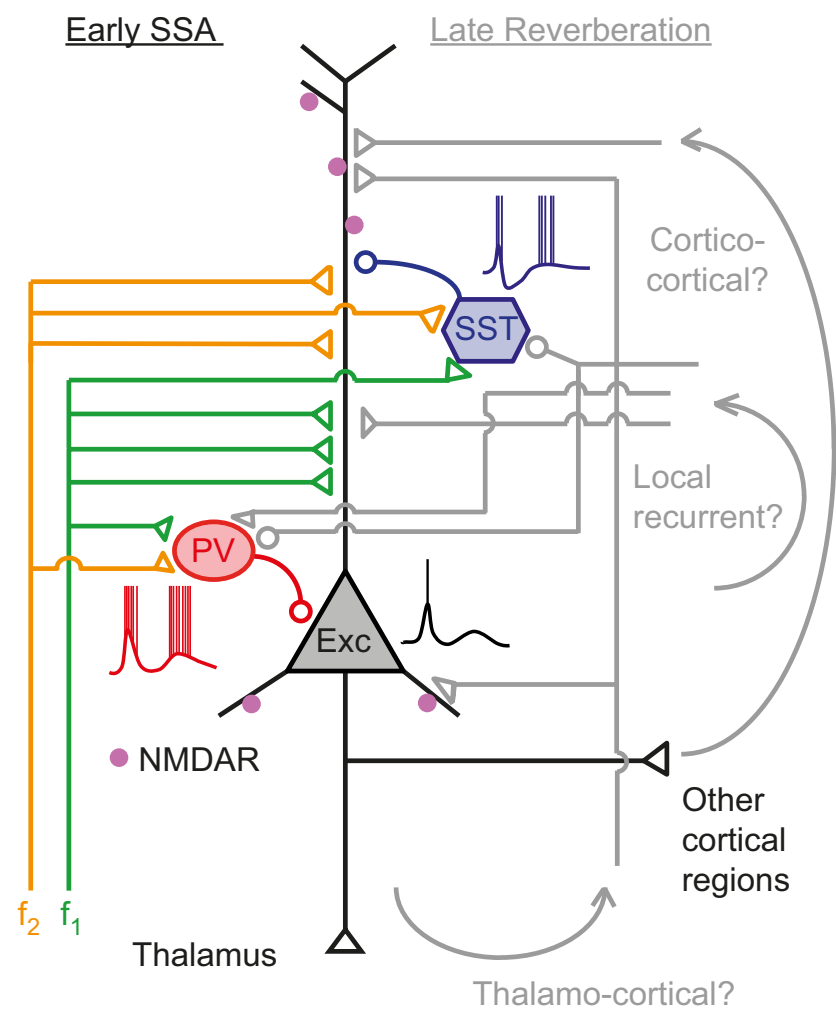

Figure 8. Schematic model of early and late oddball-evoked responses in L2/3 neurons of A1. Left: In response to oddball tones of either frequency $f 1$ (preferred) or $f 2$ (nonpreferred), the fast activation of a nonadapted synaptic channel originating from thalamus triggers the early responses in L2/3 Exc cells, as well as in SST and PV neurons. As a result a subset of L2/3 neurons becomes reactivated. Right, The recovered early oddball-evoked activity also triggers a late response component in form of a delayed network reverberation, which possibly involves local recurrent excitation and activation of larger-scale networks, e.g., thalamocortical or corticocortical loops.

affecting not only excitatory neurons but also PV and SST interneurons. The oddball tone presumably enhances both excitatory and inhibitory conductances in Al neurons through activation of nonadapted synaptic projections.

We also found that tone frequency as a stimulus feature modulates SSA, especially for the early response component, with larger SSA magnitude at subthreshold level occurring in all three neuronal classes when the oddball matched the preferred frequency (Fig. 5). At suprathreshold level, this effect was most apparent in the sparsely active pyramidal neurons. The highly stimulus-specific AP generation in L2/3 pyramidal neurons appears to depend on NMDAR signaling (Fig. 7), suggesting the involvement of active dendritic mechanisms (Smith et al., 2013; Palmer et al., 2014). In contrast, interneurons may track circuit activity with lower stimulus-specificity and reflect subthreshold inputs in a more linear fashion, which perhaps is critical for maintaining excitation-inhibition balance under a wide range of stimulus context. Such balance could be achieved by nonselective pooling of inputs from excitatory neurons (Kerlin et al., 2010; Hofer et al., 2011) or unspecific inhibition by other interneurons (Pfeffer et al., 2013). Accordingly, oddball responses in PV interneurons were independent of NMDAR signaling, indicating that the lack of nonlinear dendritic conductances (Vervaeke et al., 2012) may underlie the linear input-output transformation in interneurons (Harris and Mrsic-Flogel, 2013). 


\section{A late response component encodes stimulus context and possibly deviance detection}

We discovered an additional response component evoked by oddballs (and first tones) occurring $>100 \mathrm{~ms}$ after tone offset, which was particularly evident in pyramidal neurons. Because it mainly remained subthreshold in L2/3 Exc neurons, this late component possibly has been missed in previous extracellular studies (Ulanovsky et al., 2003; von der Behrens et al., 2009). The late component resembles thalamocortically driven "UP states" (MacLean et al., 2005; Rigas and Castro-Alamancos, 2007) and may be related to the late activation of sound-evoked "network calcium transients" (Grienberger et al., 2012). As this late network activation adapts to repetitive stimuli and is reactivated by an oddball stimulus, it shares the dependence on stimulus context (i.e., the history of preceding stimuli) with the early component. Generation of the late component may further depend on the stimulation protocol. For shorter ISI and briefer tone durations, the onset of the late component could be shifted earlier and merge with the early component (Taaseh et al., 2011).

Furthermore, we found evidence for genuine deviance detection in the oddball-evoked late component. The early responses in the many-standards paradigm were largely comparable with oddball responses (Fig. 6), suggesting that synaptic adaptation underlies the early oddball response. In contrast, late $V_{\mathrm{m}}$ depolarization was more prominent for oddball stimuli compared with the many-standards condition, suggesting that the late but not early component carries the signature of genuine deviance detection in rodent A1. The subthreshold late depolarization in L2/3 Exc cells might merely be the signature of deviance detection involving processing across cortical layers, as current-source profiles in response to oddballs indicate that SSA occurs in all A1 layers, albeit to a variable degree (Szymanski et al., 2009). Another possibility is that a small subset of $\mathrm{L} 2 / 3$ pyramidal neurons still exhibits suprathreshold late responses (Grienberger et al., 2012). It could be that oddball-evoked late spiking responses arise in middle layers receiving direct thalamocortical inputs (Metherate and Cruikshank, 1999). Excitatory cells in deeper layers may integrate supragranular inputs (Ojima et al., 1991) with nonlemniscal thalamic inputs (Kimura et al., 2003) to detect deviant stimuli and convey this information further via various corticofugal projections (Winer, 2006; Malmierca et al., 2015).

\section{Possible link of the late response component to MMN}

The features of oddball-evoked late components revealed by intracellular recordings offer a putative link to MMN measured in human EEG and MMN-like activity recorded in rodents (Umbricht et al., 2005; Nakamura et al., 2011). Middle-latency responses peaking at approximately tens of milliseconds have similar time courses to early responses during SSA (Slabu et al., 2010; Grimm et al., 2011). Nonetheless the relationship between SSA and MMN has remained elusive. In addition to both carrying true deviance information, the time course of $\mathrm{MMN}$ and the late component match surprisingly well. This becomes especially obvious when comparing the derivatives of oddball-evoked $V_{\mathrm{m}}$ responses (Fig. 4), which can serve as a first approximation of the extracellular currents that summate to generate EEG signals. Using blind intracellular recordings, a recent study reported the early oddball-evoked membrane potential responses although depolarization within the late time window was not mentioned (Hershenhoren et al., 2014). Here, we describe the precise time course and cell-type-specificity of the oddball-evoked late component. The late activity triggered by relevant stimulus context may be an important mechanism of sensory integration in behaving animals (Sachidhanandam et al., 2013).

Another critical argument is the lack of NMDAR dependence in SSA (Farley et al., 2010), but not in MMN (Tikhonravov et al., 2008), after systemic NMDAR blockade. We found that both oddball-evoked early and late components in pyramidal neurons were strongly reduced after intracellular infusion of the NMDAR antagonist MK-801. Although SSA was still present in the early subthreshold responses of Exc cells, it was significantly reduced for the late component (Fig. 7). With its NMDAR dependence, the oddball-evoked late component shares yet another feature with MMN.

The origin of the late response component remains to be elucidated. We suspect that it reflects reverberating network activity that persists beyond the actual sensory drive, similar to cortical UP states (Fig. 8). Whether such network activity may occur locally within a columnar circuit, possibly through cross-laminar interactions, or whether it requires reverberation in larger-scale networks, such as the thalamocortical or corticocortical circuitry, awaits further investigation.

\section{References}

Adesnik H, Bruns W, Taniguchi H, Huang ZJ, Scanziani M (2012) A neural circuit for spatial summation in visual cortex. Nature 490:226-231. CrossRef Medline

Anderson LA, Christianson GB, Linden JF (2009) Stimulus-specific adaptation occurs in the auditory thalamus. J Neurosci 29:7359-7363. CrossRef Medline

Antunes FM, Nelken I, Covey E, Malmierca MS (2010) Stimulus-specific adaptation in the auditory thalamus of the anesthetized rat. PLoS One 5:e14071. CrossRef Medline

Ayala YA, Malmierca MS (2012) Stimulus-specific adaptation and deviance detection in the inferior colliculus. Front Neural Circuits 6:89. CrossRef Medline

Barbour DL, Callaway EM (2008) Excitatory local connections of superficial neurons in rat auditory cortex. J Neurosci 28:11174-11185. CrossRef Medline

Duque D, Pérez-Gonzalez D, Ayala YA, Palmer AR, Malmierca MS (2012) Topographic distribution, frequency, and intensity dependence of stimulus-specific adaptation in the inferior colliculus of the rat. J Neurosci 32:17762-17774. CrossRef Medline

Duque D, Malmierca MS, Caspary DM (2014) Modulation of stimulusspecific adaptation by GABA(A) receptor activation or blockade in the medial geniculate body of the anaesthetized rat. J Physiol 592:729-743. CrossRef Medline

Farley BJ, Quirk MC, Doherty JJ, Christian EP (2010) Stimulus-specific adaptation in auditory cortex is an NMDA-independent process distinct from the sensory novelty encoded by the mismatch negativity. J Neurosci 30:16475-16484. CrossRef Medline

Fishman YI, Steinschneider M (2012) Searching for the mismatch negativity in primary auditory cortex of the awake monkey: deviance detection or stimulus specific adaptation? J Neurosci 32:15747-15758. CrossRef Medline

Gambino F, Pagès S, Kehayas V, Baptista D, Tatti R, Carleton A, Holtmaat A (2014) Sensory-evoked LTP driven by dendritic plateau potentials in vivo. Nature 515:116-119. CrossRef Medline

Garrido MI, Kilner JM, Stephan KE, Friston KJ (2009) The mismatch negativity: a review of underlying mechanisms. Clin Neurophysiol 120:453463. CrossRef Medline

Gentet LJ, Avermann M, Matyas F, Staiger JF, Petersen CC (2010) Membrane potential dynamics of GABAergic neurons in the barrel cortex of behaving mice. Neuron 65:422-435. CrossRef Medline

Gentet LJ, Kremer Y, Taniguchi H, Huang ZJ, Staiger JF, Petersen CC (2012) Unique functional properties of somatostatin-expressing GABAergic neurons in mouse barrel cortex. Nat Neurosci 15:607-612. CrossRef Medline

Grienberger C, Adelsberger H, Stroh A, Milos RI, Garaschuk O, Schierloh A, Nelken I, Konnerth A (2012) Sound-evoked network calcium transients in mouse auditory cortex in vivo. J Physiol 590:899-918. CrossRef Medline 
Grimm S, Escera C, Slabu L, Costa-Faidella J (2011) Electrophysiological evidence for the hierarchical organization of auditory change detection in the human brain. Psychophysiology 48:377-384. CrossRef Medline

Harris KD, Mrsic-Flogel TD (2013) Cortical connectivity and sensory coding. Nature 503:51-58. CrossRef Medline

Hershenhoren I, Taaseh N, Antunes FM, Nelken I (2014) Intracellular correlates of stimulus-specific adaptation. J Neurosci 34:3303-3319. CrossRef Medline

Higley MJ, Contreras D (2006) Balanced excitation and inhibition determine spike timing during frequency adaptation. J Neurosci 26:448-457. CrossRef Medline

Hippenmeyer S, Vrieseling E, Sigrist M, Portmann T, Laengle C, Ladle DR, Arber S (2005) A developmental switch in the response of DRG neurons to ETS transcription factor signaling. PLoS Biol 3:e159. CrossRef Medline

Hofer SB, Ko H, Pichler B, Vogelstein J, Ros H, Zeng H, Lein E, Lesica NA, Mrsic-Flogel TD (2011) Differential connectivity and response dynamics of excitatory and inhibitory neurons in visual cortex. Nat Neurosci 14:1045-1052. CrossRef Medline

Javitt DC, Steinschneider M, Schroeder CE, Arezzo JC (1996) Role of cortical $N$-methyl-D-aspartate receptors in auditory sensory memory and mismatch negativity generation: implications for schizophrenia. Proc Natl Acad Sci U S A 93:11962-11967. CrossRef Medline

Kerlin AM, Andermann ML, Berezovskii VK, Reid RC (2010) Broadly tuned response properties of diverse inhibitory neuron subtypes in mouse visual cortex. Neuron 67:858-871. CrossRef Medline

Kimura A, Donishi T, Sakoda T, Hazama M, Tamai Y (2003) Auditory thalamic nuclei projections to the temporal cortex in the rat. Neuroscience 117:1003-1016. CrossRef Medline

Kitamura K, Judkewitz B, Kano M, Denk W, Häusser M (2008) Targeted patch-clamp recordings and single-cell electroporation of unlabeled neurons in vivo. Nat Methods 5:61-67. Medline

Langer D, van 't Hoff M, Keller AJ, Nagaraja C, Pfäffli OA, Göldi M, Kasper H, Helmchen F (2013) HelioScan: a software framework for controlling in vivo microscopy setups with high hardware flexibility, functional diversity and extendibility. J Neurosci Methods 215:38-52. CrossRef Medline

Lavzin M, Rapoport S, Polsky A, Garion L, Schiller J (2012) Nonlinear dendritic processing determines angular tuning of barrel cortex neurons in vivo. Nature 490:397-401. CrossRef Medline

Letzkus JJ, Wolff SB, Meyer EM, Tovote P, Courtin J, Herry C, Lüthi A (2011) A disinhibitory microcircuit for associative fear learning in the auditory cortex. Nature 480:331-335. CrossRef Medline

Levy RB, Reyes AD (2012) Spatial profile of excitatory and inhibitory synaptic connectivity in mouse primary auditory cortex. J Neurosci 32:56095619. CrossRef Medline

Li LY, Xiong XR, Ibrahim LA, Yuan W, Tao HW, Zhang LI (2015) Differential receptive field properties of parvalbumin and somatostatin inhibitory neurons in mouse auditory cortex. Cereb Cortex 25:1782-1791. CrossRef Medline

MacLean JN, Watson BO, Aaron GB, Yuste R (2005) Internal dynamics determine the cortical response to thalamic stimulation. Neuron 48:811823. CrossRef Medline

Madisen L, Zwingman TA, Sunkin SM, Oh SW, Zariwala HA, Gu H, Ng LL, Palmiter RD, Hawrylycz MJ, Jones AR, Lein ES, Zeng H (2010) A robust and high-throughput Cre reporting and characterization system for the whole mouse brain. Nat Neurosci 13:133-140. CrossRef Medline

Malina KC, Jubran M, Katz Y, Lampl I (2013) Imbalance between excitation and inhibition in the somatosensory cortex produces postadaptation facilitation. J Neurosci 33:8463-8471. CrossRef Medline

Malmierca MS, Cristaudo S, Pérez-Gonzalez D, Covey E (2009) Stimulusspecific adaptation in the inferior colliculus of the anesthetized rat. J Neurosci 29:5483-5493. CrossRef Medline

Malmierca MS, Anderson LA, Antunes FM (2015) The cortical modulation of stimulus-specific adaptation in the auditory midbrain and thalamus: a potential neuronal correlate for predictive coding. Front Syst Neurosci 9:19. CrossRef Medline

Margrie TW, Meyer AH, Caputi A, Monyer H, Hasan MT, Schaefer AT, Denk W, Brecht M (2003) Targeted whole-cell recordings in the mammalian brain in vivo. Neuron 39:911-918. CrossRef Medline

May PJ, Tiitinen H (2010) Mismatch negativity (MMN), the devianceelicited auditory deflection, explained. Psychophysiology 47:66-122. CrossRef Medline

May P, Tiitinen H, Ilmoniemi RJ, Nyman G, Taylor JG, Näätänen R (1999)
Frequency change detection in human auditory cortex. J Comput Neurosci 6:99-120. CrossRef Medline

Metherate R, Cruikshank SJ (1999) Thalamocortical inputs trigger a propagating envelope of gamma-band activity in auditory cortex in vitro. Exp Brain Res 126:160-174. CrossRef Medline

Näätänen R (1984) In search of a short-duration memory trace of a stimulus in the human brain. In: Human action and personality. Essays in honour of Martii Takala (Pulkkinen L, Lyytinen P, eds), pp 29-43. Jyvaeskylae, Finland: University of Jyvaeskylae.

Näätänen R, Jacobsen T, Winkler I (2005) Memory-based or afferent processes in mismatch negativity (MMN): a review of the evidence. Psychophysiology 42:25-32. CrossRef Medline

Näätänen R, Paavilainen P, Rinne T, Alho K (2007) The mismatch negativity (MMN) in basic research of central auditory processing: a review. Clin Neurophysiol 118:2544-2590. CrossRef Medline

Nakamura T, Michie PT, Fulham WR, Todd J, Budd TW, Schall U, Hunter M, Hodgson DM (2011) Epidural auditory event-related potentials in the rat to frequency and duration deviants: evidence of mismatch negativity? Front Psychol 2:367. CrossRef Medline

Nelken I (2014) Stimulus-specific adaptation and deviance detection in the auditory system: experiments and models. Biol Cybern 108:655-663. CrossRef Medline

Nelken I, Ulanovsky N (2007) Mismatch negativity and stimulus-specific adaptation in animal models. J Psychophysiol 21:214-223. CrossRef

Ojima H, Honda CN, Jones EG (1991) Patterns of axon collateralization of identified supragranular pyramidal neurons in the cat auditory cortex. Cereb Cortex 1:80-94. CrossRef Medline

Palmer LM, Shai AS, Reeve JE, Anderson HL, Paulsen O, Larkum ME (2014) NMDA spikes enhance action potential generation during sensory input. Nat Neurosci 17:383-390. CrossRef Medline

Pérez-González D, Malmierca MS (2014) Adaptation in the auditory system: an overview. Front Integr Neurosci 8:19. CrossRef Medline

Pérez-González D, Hernández O, Covey E, Malmierca MS (2012) GABA(A)-mediated inhibition modulates stimulus-specific adaptation in the inferior colliculus. PLoS One 7:e34297. CrossRef Medline

Pfeffer CK, Xue M, He M, Huang ZJ, Scanziani M (2013) Inhibition of inhibition in visual cortex: the logic of connections between molecularly distinct interneurons. Nat Neurosci 16:1068-1076. CrossRef Medline

Pi HJ, Hangya B, Kvitsiani D, Sanders JI, Huang ZJ, Kepecs A (2013) Cortical interneurons that specialize in disinhibitory control. Nature 503: 521-524. CrossRef Medline

Picton TW, Alain C, Otten L, Ritter W, Achim A (2000) Mismatch negativity: different water in the same river. Audiol Neurootol 5:111-139. CrossRef Medline

Rigas P, Castro-Alamancos MA (2007) Thalamocortical Up states: differential effects of intrinsic and extrinsic cortical inputs on persistent activity. J Neurosci 27:4261-4272. CrossRef Medline

Rudy B, Fishell G, Lee S, Hjerling-Leffler J (2011) Three groups of interneurons account for nearly $100 \%$ of neocortical GABAergic neurons. Dev Neurobiol 71:45-61. CrossRef Medline

Sachidhanandam S, Sreenivasan V, Kyriakatos A, Kremer Y, Petersen CC (2013) Membrane potential correlates of sensory perception in mouse barrel cortex. Nat Neurosci 16:1671-1677. CrossRef Medline

Shelley AM, Ward PB, Catts SV, Michie PT, Andrews S, McConaghy N (1991) Mismatch negativity: an index of a preattentive processing deficit in schizophrenia. Biol Psychiatry 30:1059-1062. CrossRef Medline

Slabu L, Escera C, Grimm S, Costa-Faidella J (2010) Early change detection in humans as revealed by auditory brainstem and middle-latency evoked potentials. Eur J Neurosci 32:859-865. CrossRef Medline

Smith PH, Populin LC (2001) Fundamental differences between the thalamocortical recipient layers of the cat auditory and visual cortices. J Comp Neurol 436:508-519. CrossRef Medline

Smith SL, Smith IT, Branco T, Häusser M (2013) Dendritic spikes enhance stimulus selectivity in cortical neurons in vivo. Nature 503:115-120. CrossRef Medline

Szymanski FD, Garcia-Lazaro JA, Schnupp JW (2009) Current source density profiles of stimulus-specific adaptation in rat auditory cortex. J Neurophysiol 102:1483-1490. CrossRef Medline

Taaseh N, Yaron A, Nelken I (2011) Stimulus-specific adaptation and deviance detection in the rat auditory cortex. PLoS One 6:e23369. CrossRef Medline

Tamamaki N, Yanagawa Y, Tomioka R, Miyazaki J, Obata K, Kaneko T 
(2003) Green fluorescent protein expression and colocalization with calretinin, parvalbumin, and somatostatin in the GAD67-GFP knock-in mouse. J Comp Neurol 467:60-79. CrossRef Medline

Tan AY, Wehr M (2009) Balanced tone-evoked synaptic excitation and inhibition in mouse auditory cortex. Neuroscience 163:1302-1315. CrossRef Medline

Taniguchi H, He M, Wu P, Kim S, Paik R, Sugino K, Kvitsani D, Fu Y, Lu J, Lin Y, Miyoshi G, Shima Y, Fishell G, Nelson SB, Huang ZJ (2011) A resource of Cre driver lines for genetic targeting of GABAergic neurons in cerebral cortex. Neuron 71:995-1013. CrossRef Medline

Tikhonravov D, Neuvonen T, Pertovaara A, Savioja K, Ruusuvirta T, Näätänen R, Carlson S (2008) Effects of an NMDA-receptor antagonist MK-801 on an MMN-like response recorded in anesthetized rats. Brain Res 1203:97-102. CrossRef Medline

Todd J, Michie PT, Schall U, Ward PB, Catts SV (2012) Mismatch negativity $(\mathrm{MMN})$ reduction in schizophrenia-impaired prediction-error generation, estimation or salience? Int J Psychophysiol 83:222-231. CrossRef Medline

Ulanovsky N, Las L, Nelken I (2003) Processing of low-probability sounds by cortical neurons. Nat Neurosci 6:391-398. CrossRef Medline

Umbricht D, Schmid L, Koller R, Vollenweider FX, Hell D, Javitt DC (2000) Ketamine-induced deficits in auditory and visual context-dependent pro- cessing in healthy volunteers: implications for models of cognitive deficits in schizophrenia. Arch Gen Psychiatry 57:1139-1147. CrossRef Medline

Umbricht D, Vyssotki D, Latanov A, Nitsch R, Lipp HP (2005) Deviancerelated electrophysiological activity in mice: is there mismatch negativity in mice? Clin Neurophysiol 116:353-363. CrossRef Medline

Vervaeke K, Lorincz A, Nusser Z, Silver RA (2012) Gap junctions compensate for sublinear dendritic integration in an inhibitory network. Science 335:1624-1628. CrossRef Medline

von der Behrens W, Bäuerle P, Kössl M, Gaese BH (2009) Correlating stimulus-specific adaptation of cortical neurons and local field potentials in the awake rat. J Neurosci 29:13837-13849. CrossRef Medline

Wehr M, Zador AM (2003) Balanced inhibition underlies tuning and sharpens spike timing in auditory cortex. Nature 426:442-446. CrossRef Medline

Wilson NR, Runyan CA, Wang FL, Sur M (2012) Division and subtraction by distinct cortical inhibitory networks in vivo. Nature 488:343-348. CrossRef Medline

Winer JA (2006) Decoding the auditory corticofugal systems. Hear Res 212: 1-8. CrossRef Medline

Zhang LI, Tan AY, Schreiner CE, Merzenich MM (2003) Topography and synaptic shaping of direction selectivity in primary auditory cortex. Nature 424:201-205. CrossRef Medline 